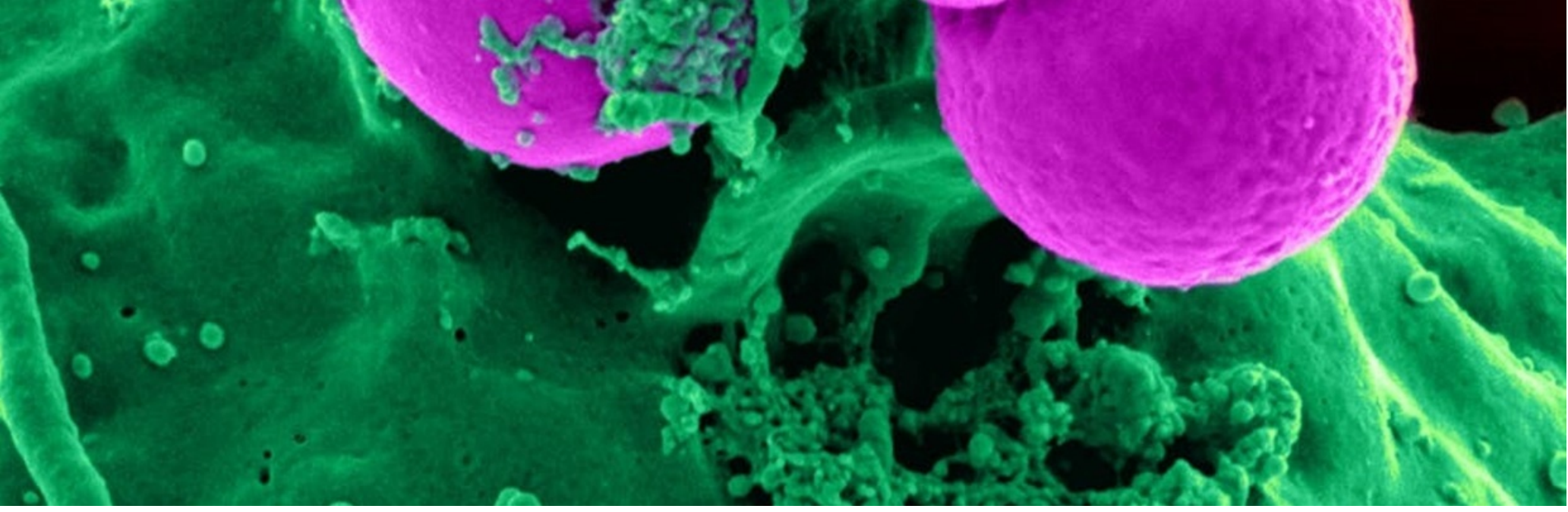

\title{
Optimization of long-term Breast Cancer Cell Culture using live Imaging in an automated Perfusion System
}

\author{
Authors: Dario Ruarte \\ Submitted: $\quad$ 17. August 2020 \\ Published: $\quad$ 8. September 2020 \\ Volume: 7 \\ Issue: 5 \\ Affiliation: Universitätsklinikum Freiburg, Univeristy of Buenos Aires \\ Languages: \\ Keywords: \\ Categories: $\quad$ Demetrios Project, Life Sciences, Medicine \\ DOI: $\quad$ 10.17160/josha.7.5.706 \\ English \\ Breast Cancer, Automation, Perfusion, Microscopy, Image \\ Analysis, Microdevices, Live Imaging.
}

\section{Abstract:}

A significant quantity of questions remains in cellular biology. Some of them cannot be answered by applying traditional analytical techniques and request the development of new tools for research. Nowadays, the integration of microdevices and analytical platforms enables the acquisition of biological data in an agile and low-cost manner. Additionally, perfusion technologies allow us to recreate physiological microenvironments. For this reason, the integration of live-cell microscopy, perfusion, and microsystems, will enable control of the delivery of soluble factors and the tracking of single cells. These platforms have a vast potential to result in a better understanding of cell behavior, generating evidence for potential predictive models for disease treatment. We have developed a robust live-imaging fluidic system for studying breast cancer cells. Our data suggest fast and short pulses as the preferred strategy for perfused assays. This system will be the basis for further analysis of the effect of stimulatory growth factors and cytotoxic or cytostatic aoents with theraneutic notential Furthermore we offer an overview of

\section{JOSHA Jomana Isameane. Humanities and Arts}



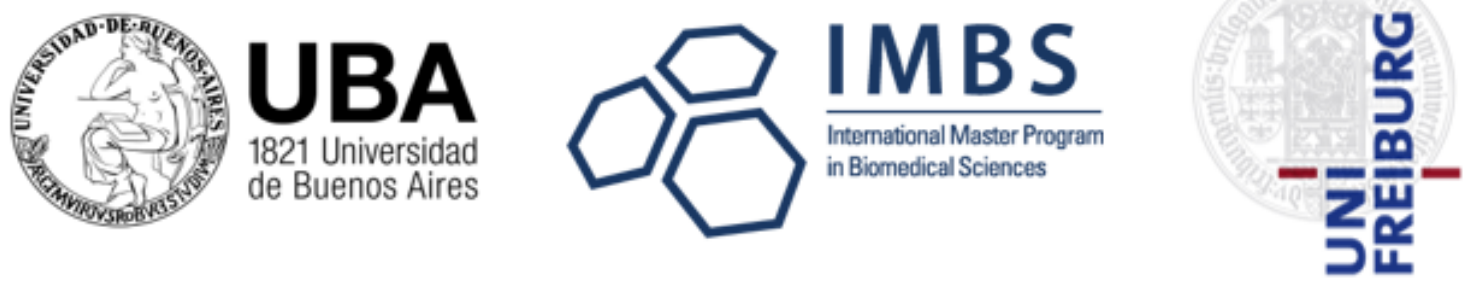

\section{OPTIMIZATION OF LONG-TERM}

BREAST CANCER CELL CULTURE

USING LIVE IMAGING IN AN

\section{AUTOMATED PERFUSION SYSTEM}

For the degree of Master of Science

Author: Pharm. Dario Ruarte

Cohort: $2018-2020$

Director: Prof. Dr. Joschka Bödecker

Co-Director: Dr. Maximiliano Perez

Faculty of Pharmacy and Biochemistry, Faculty of Medicine Universidad de Buenos Aires, Argentina

Faculty of Medicine -

Albert Ludwigs University of Freiburg, Germany 

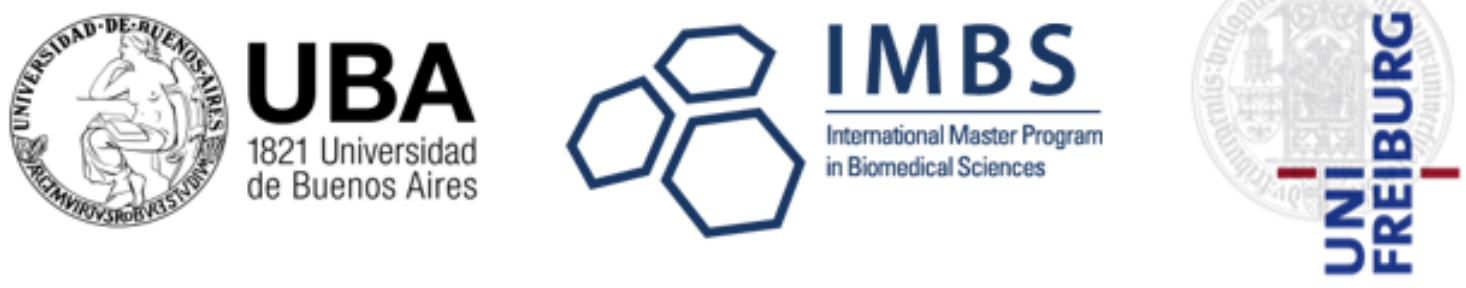

2020

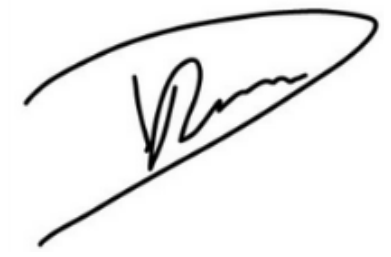

Author: Pharm. Dario Gabriel Ruarte
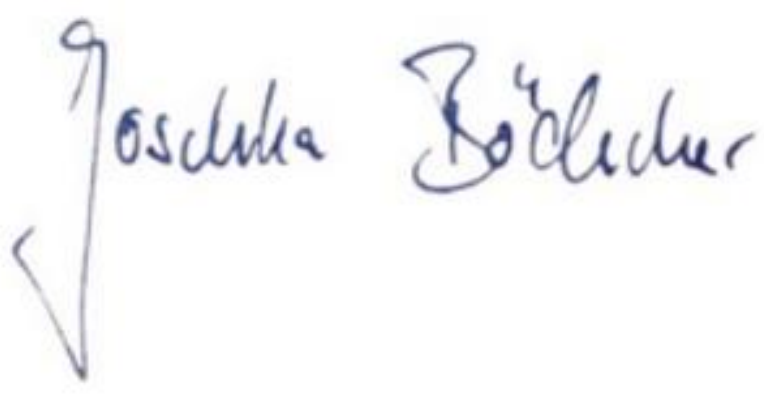

Director: Prof. Dr. Joschka Bödecker

Co-Director: Dr. Maximiliano Perez 


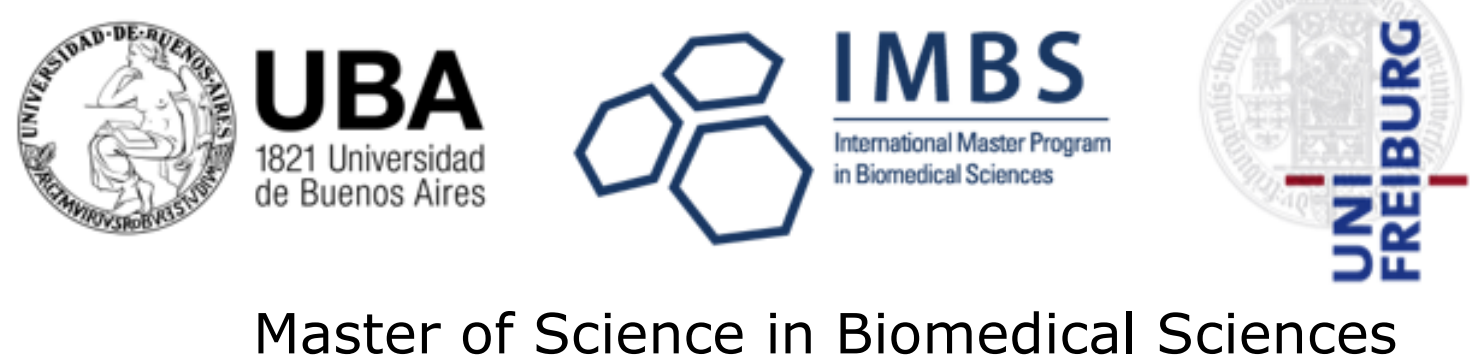

\section{Statement for the Master's Thesis}

Hereby I confirm that

- I completed the submitted master's thesis independently.

- I used no sources or aids other than those stated, and all verbatim or conceptual content taken from other works has been identified as such.

- the submitted master's thesis was or is not, either in full or in large part the subject of another examination process.

- the electronic version of the master's thesis submitted is in content and format the same as the printed version, and

- the master's thesis has not yet been published.

$04 / 05 / 2020$

Date
Ruarte, Darío Gabriel

Surname, name

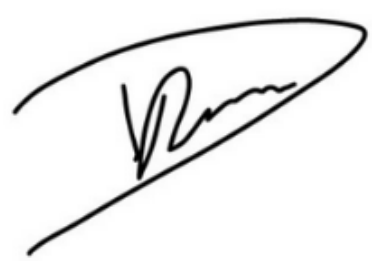

Signature 


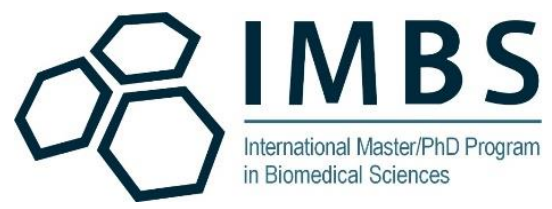

Institute of Molecular Medicine and Cell Research - Master Program M.Sc. Biomedical Sciences -

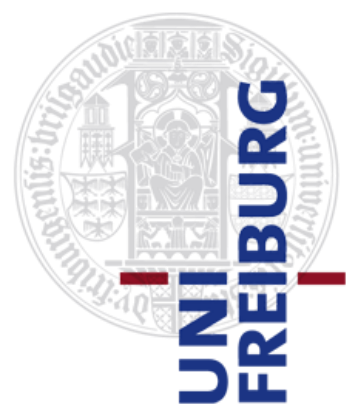


Declaration to the Master Thesis

Hereby I declare on oath that I wrote my Master Thesis myself and did not use other sources than mentioned as resources.

04.05.2020 Ruarte, Darío Gabriel

Date Name, First Name

Signature of the student

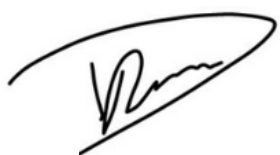

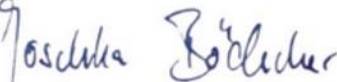

The Master Thesis can be accessible to the public 24 months after the completion of the procedure.

04.05 .2020

Date

04.05 .2020

Date

04.05 .2020

Date
Signature of the Director

Name: Prof. Dr. Joschka Bödecker

Signature of the Co- Director

Name: Dr. Maximiliano Sebastian Perez

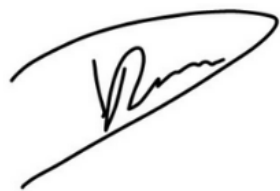

Signature of the student Name: Darío Gabriel Ruarte 


\section{Abstract}

A significant quantity of questions remains in cellular biology. Some of them cannot be answered by applying traditional analytical techniques and request the development of new tools for research. Nowadays, the integration of microdevices and analytical platforms enables the acquisition of biological data in an agile and low-cost manner. Additionally, perfusion technologies allow us to recreate physiological microenvironments.

For this reason, the integration of live-cell microscopy, perfusion, and microsystems, will enable control of the delivery of soluble factors and the tracking of single cells. These platforms have a vast potential to result in a better understanding of cell behavior, generating evidence for potential predictive models for disease treatment. We have developed a robust live-imaging fluidic system for studying breast cancer cells. Our data suggest fast and short pulses as the preferred strategy for perfused assays. This system will be the basis for further analysis of the effect of stimulatory growth factors and cytotoxic or cytostatic agents with therapeutic potential. Furthermore, we offer an overview of the challenges and considerations in the development of automated microsystems. 


\section{Acknowledgements}

The author cannot be more grateful to the committee for their continuous support and encouragement: Prof. Dr. Drs. h.c Roland Mertelsmann, Dr. Marie Follo, Prof. Dr. Joschka Bödecker, and Dr. Maximiliano Perez. This student sincerely appreciates the learning opportunities provided for the board.

This project could not start without all the effort and advice of Engr. Gustavo Rossero, and M.Phil. Ana Peñaherrera.

The daily work could not be better without those fellow lab mates Gisella Pattarone, Julia Pinter, Felicitas Pilz, Denis Raith, and the core facilities team: Klauss, Dieter, Jan, and Alexsandra.

This student, thanks the director of the Department of Internal Medicine I, Prof. Justus Duyster, and Biothera foundation for the funding provided to the development of the thesis.

The author would like to express sincere gratitude to Prof. Christopher Borner, Dr. Marta Mollerach, Bärbel Schätzle, and authorities of both faculties for the accomplishment of this first cohort of the double master.

Finally, this researcher would like to thanks his family and his biologist friends who answered the rarest questions which someone can make during off-working hours: Gustavo Carrizo, Ignacio Gonzalez Perez, and Laura Faletti. 


\section{Abbreviations and Symbols III}

AC: Adriamycin - Cyclophosphamide

AC-T: Adriamycin - Cyclophosphamide - Taxol

cDMEM: complemented Dulbecco's Modified Eagle Media

ER: Estrogen Receptor

ERBB2: Receptor tyrosine-protein kinase erbB-2

FBS: Fetal Bovine Serum

FSS: Flow Shear Stress

h: Hour

HER: Hormone Estrogen Receptor

HR: Hormone Receptor

PBS: Phosphate Buffered Saline

PDMS: Polydimethylsiloxane

RPMI: Roswell Park Memorial Institute Media

TC: Taxol - Cyclophosphamide

t: Time 


\section{Content}

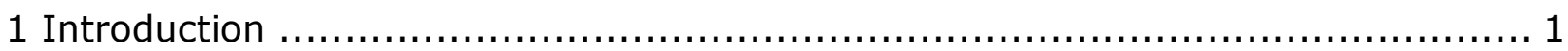

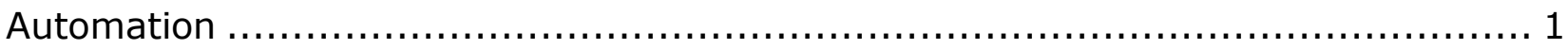

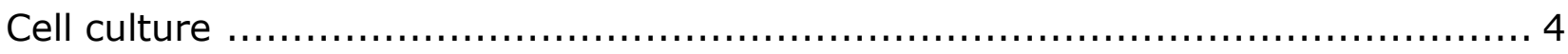

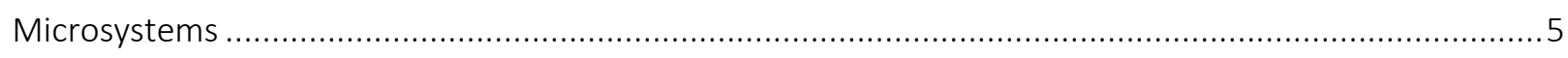

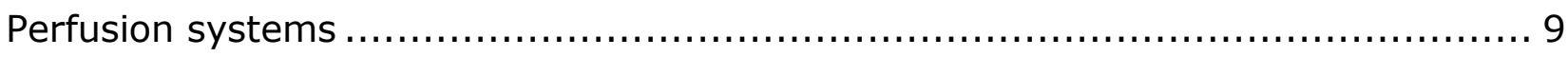

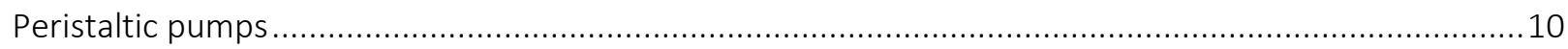

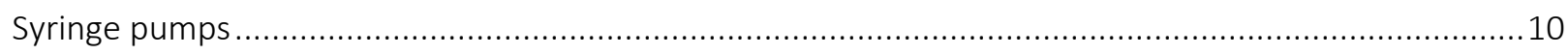

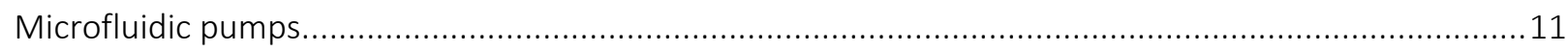

Live-cell imaging and Evaluation of Cell Health ..................................... 11

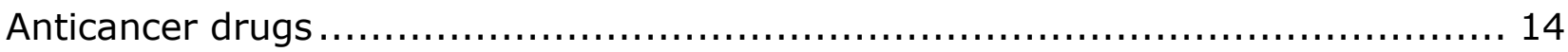

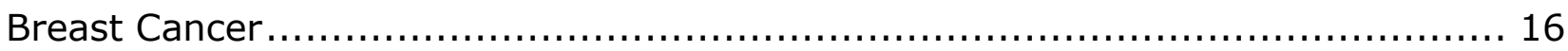

2 Materials and Methods ............................................................. 19

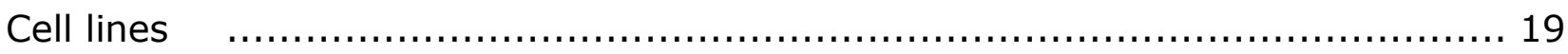

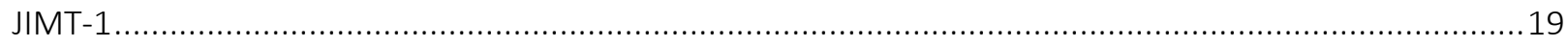

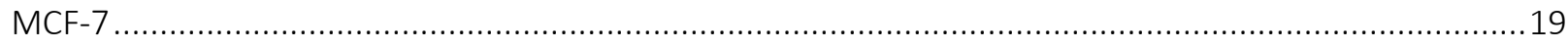

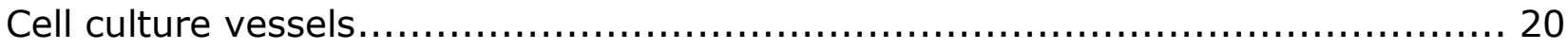

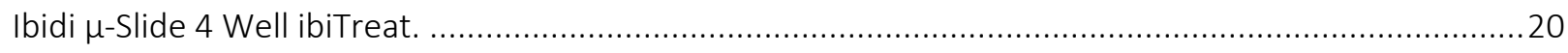

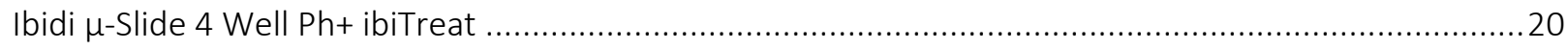

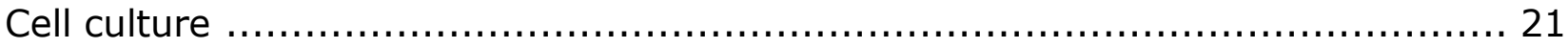

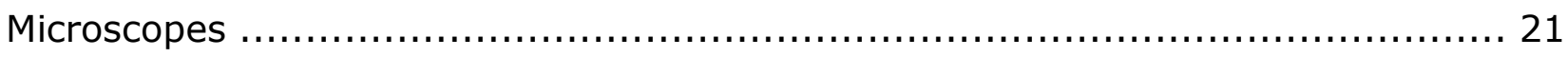

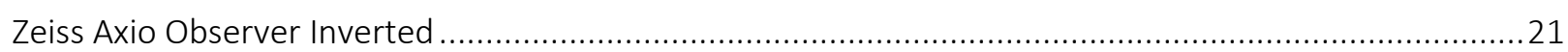

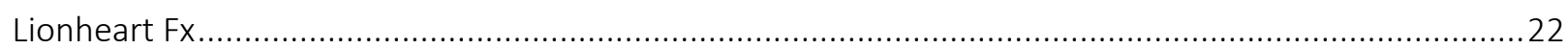

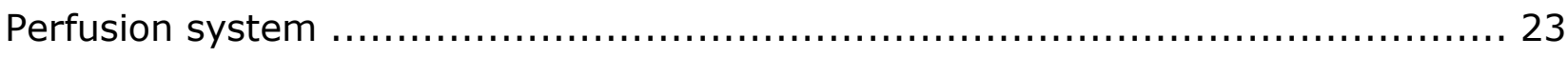

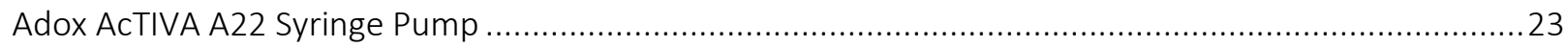

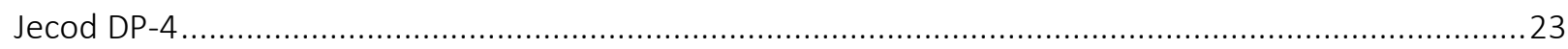

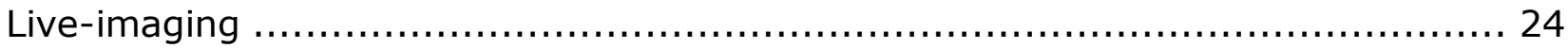

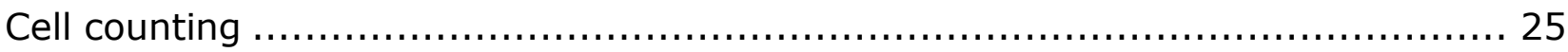

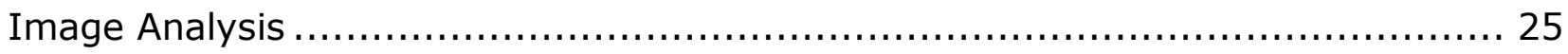

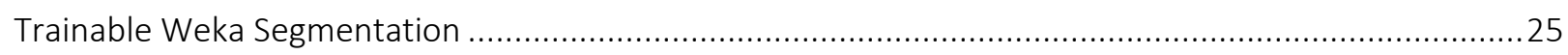


Deep Learning Algorithm

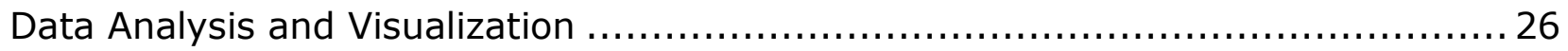

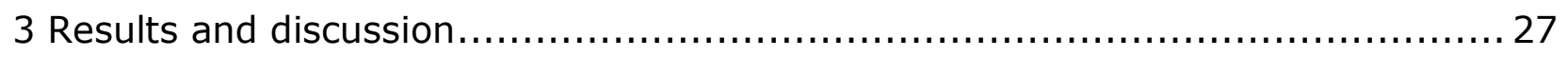

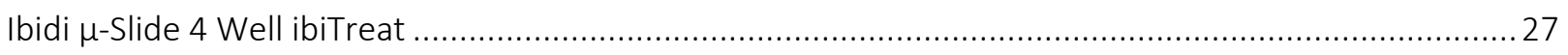

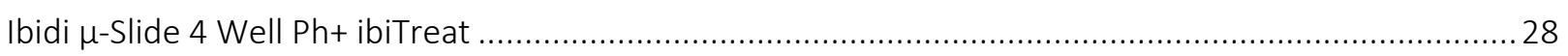

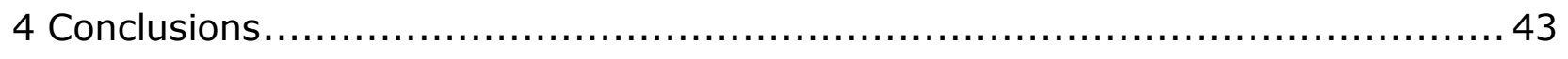

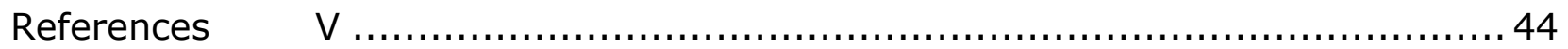




\section{Introduction}

Cell cultures are highly dynamic. This dynamic feature of cell cultures could lead to different results, even if the same protocols were applied(Hines et al., 2014). Scientists are aware of the ongoing reproducibility crisis. A survey on Nature journal of 1576 researchers has shown that more than $70 \%$ have tried and failed to reproduce another scientist's experiments, and more than half have failed to reproduce their experiments(Baker \& Penny, 2016).

The accessibility of a design to perform live imaging analysis with automated perfusion could help us not only to reproduce more realistic conditions but also to obtain much more information about our living system, increasing the efficiency and robustness of the assays, and potentially an early revelation of variability. However, what kind of conditions are best suited for cells in a microfluidic perfusion system are still unclear. In these experiments, we expand the knowledge to enable efficient automated experiments down the line.

\section{Automation}

The importance of continuous long-term observation of cell cultures has been recognized for over a century but has been limited by technology(Coutu \& Schroeder, 2013). The advance on automated microscopy provides tools to follow and analyze the cultured cells carefully, generating a tremendous amount of image data. The fourth industrial revolution suggests the integration of modern technologies and promises to be the age of artificial intelligence (Figure 1)(Demandbase, n.d.).

We hypothesize that the clue to optimize cell cultures can be hidden behind the limitations of the human perception (Figure 2)(Danuser, 2011). This concept, combined with new machine learning algorithms, will enable the capitalization of the information obtained from the cell image analysis. Nowadays, researchers developed algorithms allowing not only to recognize phenotypes from image data but also to 
control of bacterial populations in bioreactors(Sommer \& Gerlich, 2013; Treloar et al., 2018). 


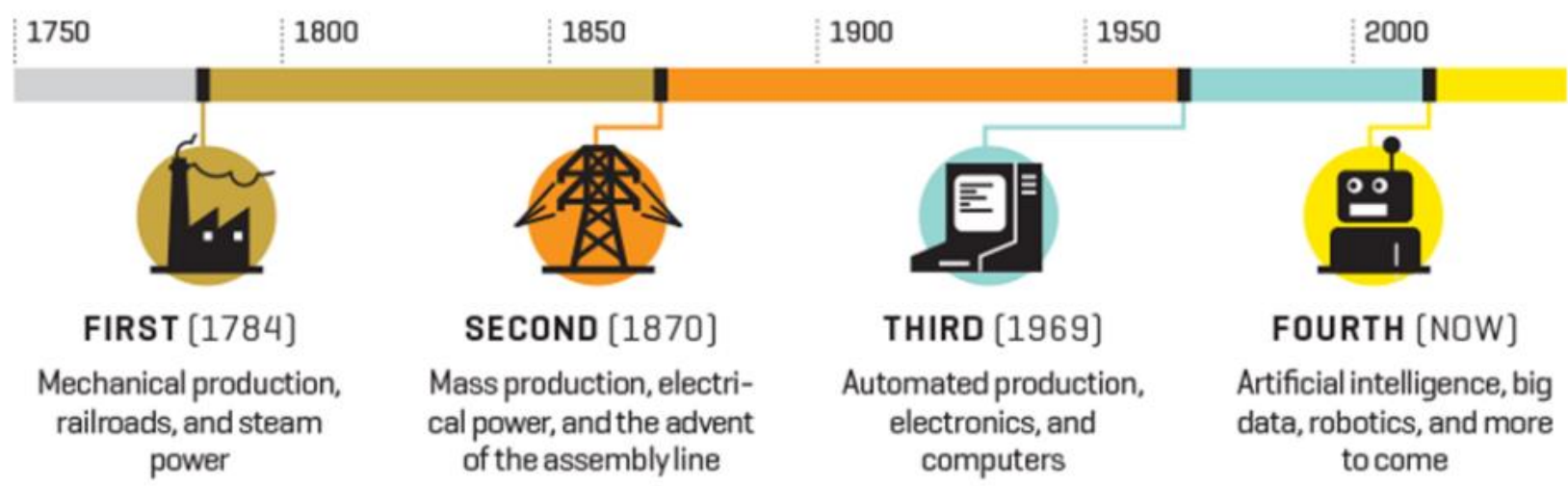

Figure 1. The four stages of industrial revolution(Demandbase, n.d.). The current fourth revolution is characterized by the combination of digital, biological and physical terhnolnaiec

In concordance with the words Professor John Ioannidis, who said, "the replication has more value to discovery" and the principles on "Good Cell Culture Practice" (GCCP)(Pamies et al., 2018), our first steps are in order to validate the system.

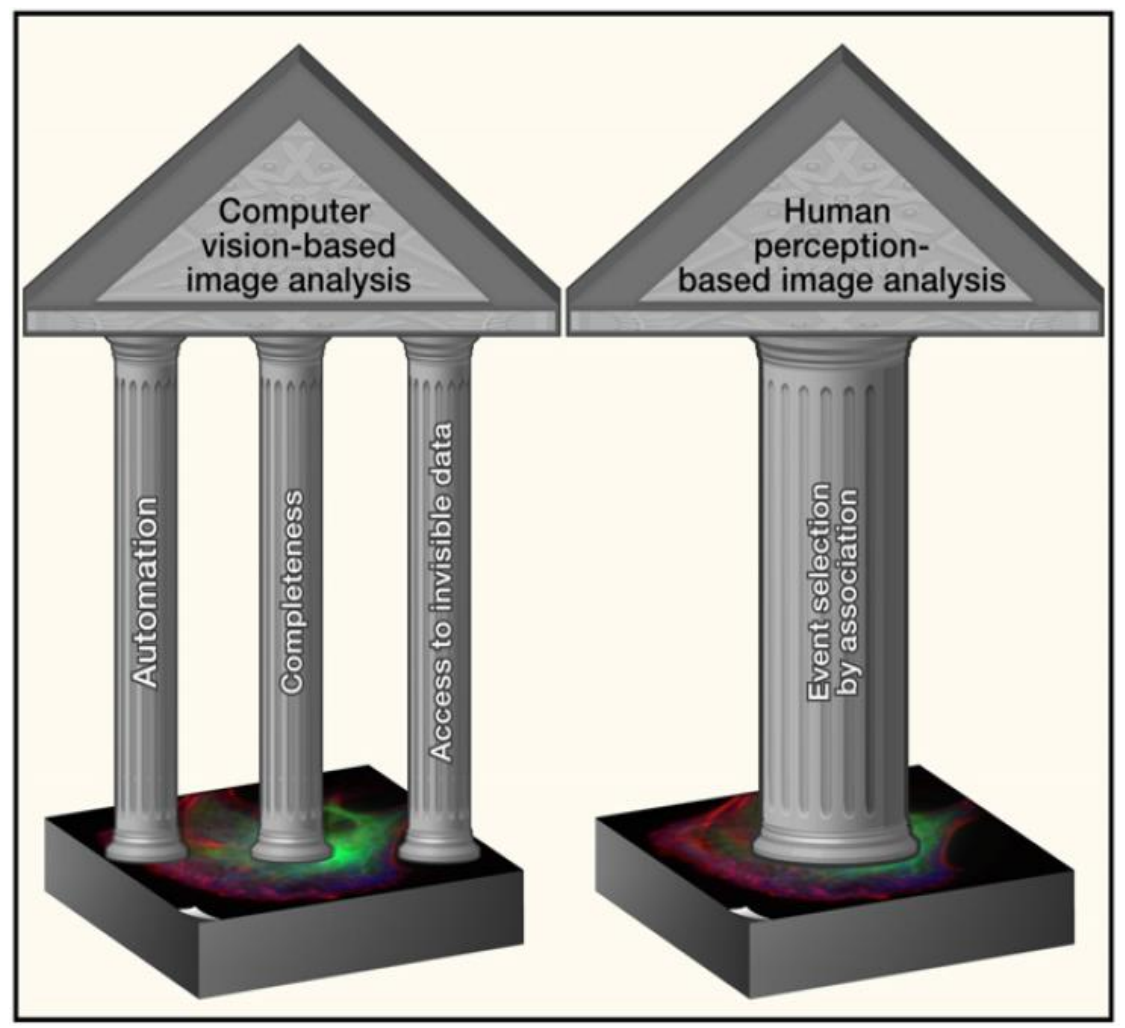

Figure 2. The strengths of computer vision and human vision in image analysis. Computer vision is an application area of Artificial Intelligence (AI) it is based in three statements: provide automation of the analysis, generate completeness in the data in that every image event fulfilling set selection criteria is considered by the analysis, and give access to processes underlying the image content that are not visible(Danuser, 2011). 


\section{Cell culture}

Almost seventy years have passed since George and Margarite Gey, former scientists at Johns Hopkins Hospital Baltimore, received a cervical cancer tissue sample that would be the mother of the first established human cell line. The adenocarcinoma biopsy taken from Henrietta Lacks will lead to the HeLa cells that are well known by the scientific community, not only for its usage but also for its intensely dissemination(Huether-Franken, 2017; Jedrzejczak-Silicka, 2017).

Since this breakthrough event, cells were cultivated, exposed to irradiation, infected, and sent to space, all on behalf of science(NIH Office of Science Policy, n.d.). Live organism cultures are widely used for drug testing, the prime matter of bioprinters, production of therapeutic proteins, and monoclonal antibodies(Corsello et al., 2020; Ecker et al., 2015; Vijayavenkataraman et al., 2018). Moreover, human cell cultures are expanding terrain as possible personalized therapies(Farina et al., 2017; Y. Liu et al., 2017; Trounson et al., 2011). In the future, therapies based on tissue and organ culture could play a pivotal role in overcoming currently irreversible health conditions. So much is the importance of cellular behavior that scientists attempt to develop mathematical models and even games to expand knowledge barriers(Mertelsmann \& Georg, 2016; Oña \& Lachmann, 2020).

However, there are also challenges, disadvantages, and limitations of the classic culture methods(Geraghty et al., 2014; Jedrzejczak-Silicka, 2017). For instance, typical static in vitro culture does not reflect the in vivo scenario creating a nonphysiological environment. As a solution, microscale devices allowing perfusion are developed continuously and proposed as in vitro models(Ando et al., 2017; Ayuso et al., 2016; Becker et al., 2019; Yeo et al., 2011). In order to obtain a comprehensive knowledge of cell function and behavior, it would be desirable to develop experimental methods that could help to interpret the physical and morphological outputs beyond the conventional practices based on chemical outcomes (Figure 3)(Azuaje-Hualde et al., 2017). Therefore, we want to define the experimental parameters to obtain reliable results in a controlled environment in a perfused microsystem. 


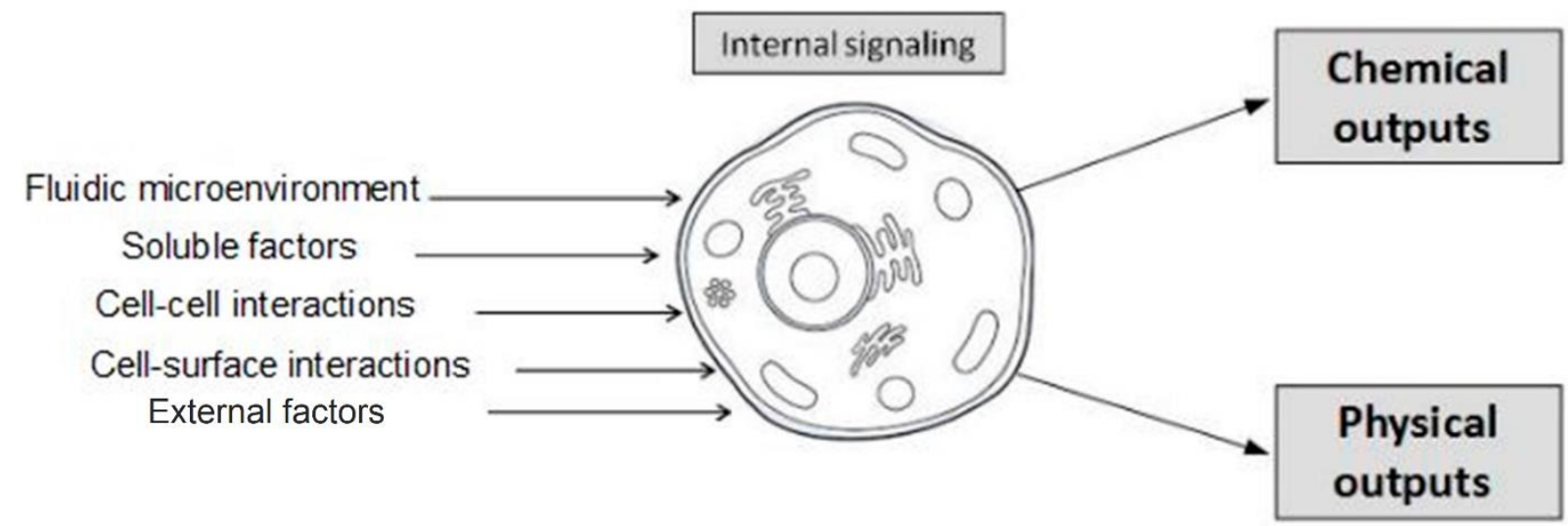

Figure 3. Input signals induce internal signaling of cells and modulate their outputs, affecting cell behavior(Azuaje-Hualde et al., 2017). Several aspects can be considered as input signals, thereupon explore models to mimic physiological conditions will expand the knowledge of cell behavior.

\section{Microsystems}

During the last twenty years, key developments have been addressed in the area of microtechnology, which allows introducing control and complexity over a full range of

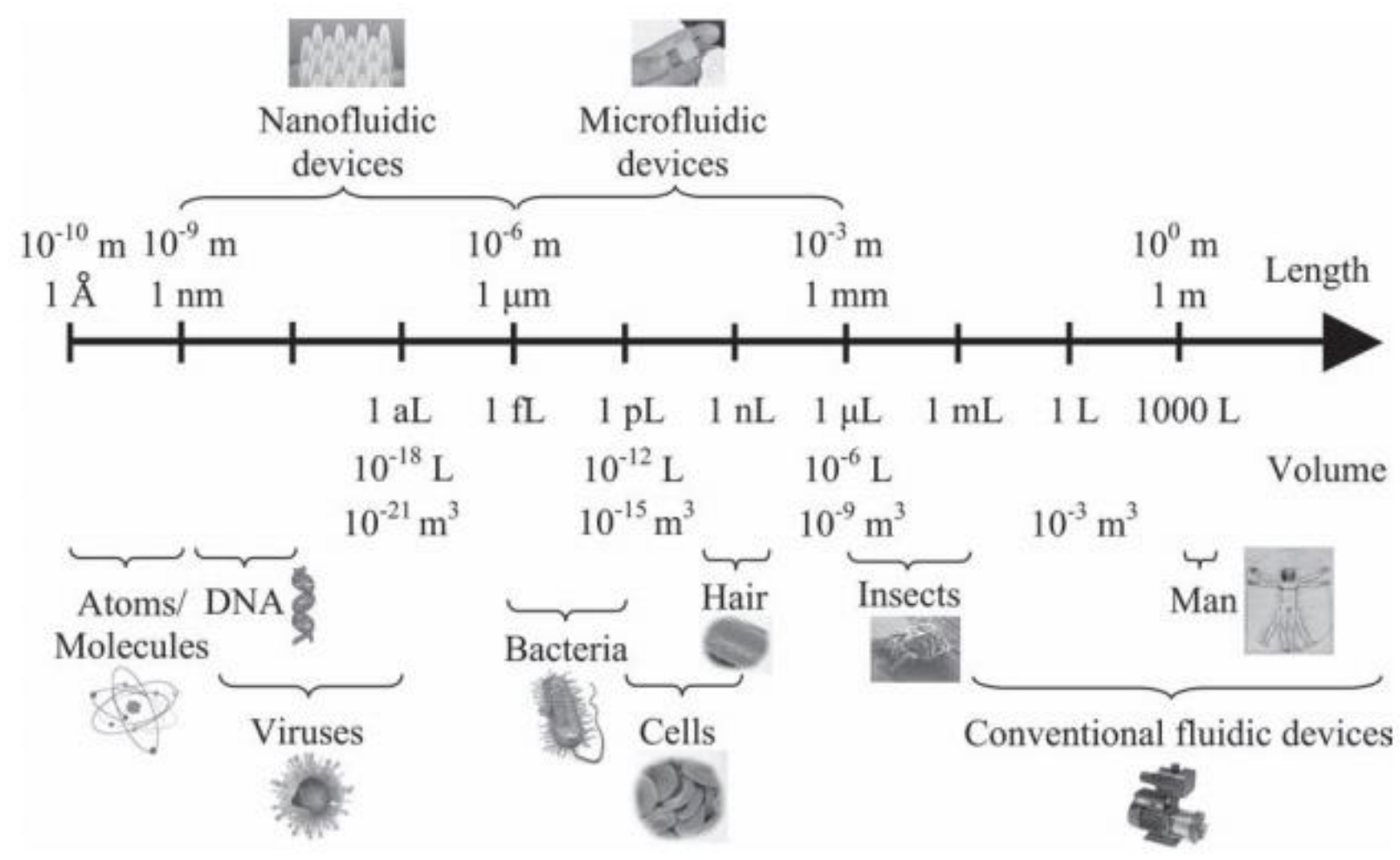

Figure 4. Characteristic length scales (approximate) of micro and nanosystems in relation to various biological entities ${ }^{23}$. Micro and nanofluidic devices appeared as an approach which decreases sample and reagents consumptions reducing the overall costs. 
environmental factors at the microscale level(Ando et al., 2017; Azuaje-Hualde et al., 2017; Mertelsmann \& Georg, 2016) (Figure 4).

However, the device microenvironment itself may induce undesirable effects on cell health, shape, and behavior, leading to bias, failure, or lack of robustness of the experiments. Therefore, not only the correct device operation but also the designs have significant relevance at the microscale. For this reason, two critical considerations are the characteristics of the cells intended to be used within the device and the goal of the model we want to develop(Green \& Yamada, 2007; Pampaloni et al., 2007; Varma \& Voldman, 2018). For instance, scientists aim to generate vesselon-a-chip models to study physiological and pathophysiological conditions in adapted hydrogel structures with internal microchannels(Nie et al., 2018).

Usually, cells maintained in culture have media in excess. Nevertheless, when they are cultured at the microscale, it is necessary to consider well or channel size, as well as transport timescales, to ensure access to nutrients. Besides, the functionalization of those surfaces plays a vital role. In adherent cell cultures, appropriate coating of the wells must be chosen in order not to compromise the health of cells. Material bulk and surface properties can impact cell viability and function(L. Chen et al., 2018; Ferrari et al., 2019; Varma \& Voldman, 2018).

As we mentioned before, cells are cultured at the macroscale, but it is necessary to step into microscale environments. Fundamentally, nutrients and ion imbalances must be prevented in cell suspensions before allocating the cells on the devices. Long term cell culture devices need to provide cells with an adequate amount of oxygen and nutrients while removing waste products to maintain cellular homeostasis. On the other hand, the excess of media will dilute autocrine factors essential for cell growth, demonstrating how crucial it is to determine the balance between waste removal and media renewal(Varma \& Voldman, 2018). In previous studies, different perfusion strategies were analyzed searching for an optimal robust long-term microfluidic cell culture(Giulitti et al., 2013). Computational simulations suggested that different delivery strategies result in different temporal profiles of accumulation and washing out of endogenous and exogenous factors, respectively. These strategies were defined by a parameter $\varphi=\mathrm{t}$ perfusion/t cycle, which is the ratio between the perfusion time and the duration of a single cycle. Assuming a 6 hours cycle, three cases were considered: a continuous strategy $(P 0)$, characterized by $\varphi=1$, and two periodic strategies, one 
with a fast-media pulse (P1), $\varphi=0.02$, and one with a long media pulse (P2), $\varphi=$ 0.25 . In each case, a volume of twice of the chamber was perfused during 6 hours of a single cycle. The authors exposed cultures to the same overall amount of medium with different temporal profiles and analyzed homogeneity, cell morphology, and phenotype(Giulitti et al., 2013). In this research, we evaluate those strategies in our perfused system, and additionally, traditional static cell culture was performed and analyzed as a control (Table 1 ).

There are many recommendations to maintain viable and healthy cells on microdevices. Since cells are manipulated and cultured in liquid environments, fluid shear stress (FSS) is always involved. Even if FSS can produce benefits in cells such as maintenance of endothelial cell function(Topper \& Gimbrone, 1999), mostly, it is pointed out as a stressor(Kolnik et al., 2012). An unappropriated amount of FSS can not only induce morphology changes but also complex biological cascades, increasing the amount of reactive oxygen species and compromising the viability (Figure 5)(Giulitti et al., 2013; Varma \& Voldman, 2018). 
Furthermore, the method applied to introduce the cells can produce variations on the distribution generating abnormal allocations. We must keep in mind the effect of gravity to promote a homogeneous seeding practice. In other words, regardless of the device to be used, either pipette or syringe, we must consider where gravity tends to settle the cells.

In addition, bubbles are a source of unpredictable experiment failure. Although the introduction of bubbles could be prevented by several methods, for instance, by pretreatment of the media with sonication and vacuum, occasionally, it is not enough to prevent their development. Introducing commercial and self-made de-bubblers can contribute to the system to promote a bubble-free environment(Pereiro et al., 2019; Zhu et al., 2019). Nevertheless, bubble generation is regularly related to how the whole system and mainly, the device is used or maintained over time. For example, it is highly recommended for PDMS or gas-permeable culture devices to preequilibrate in the appropriate $\mathrm{CO}_{2}$ environment previous cell culture because this routine will decrease the probability of bubble presence. As a recommendation, working at a pressure above atmospheric pressure (pushing liquids) avoids bubble introduction through permeable devices that can occur when operating below

Table 1. Perfusion strategies.

\begin{tabular}{|c|ccccc|}
\hline REGIME & $\begin{array}{c}\text { FLOW RATE } \\
(\mu \text { L/MIN })\end{array}$ & $\begin{array}{c}\text { PERFUSION } \\
(\text { MIN })\end{array}$ & $\begin{array}{c}\text { CYCLE } \\
(\text { MIN })\end{array}$ & $\begin{array}{c}\text { MEDIA PER CYCLE } \\
(\mu \mathrm{L})\end{array}$ & $\Phi$ \\
\hline P0 & 3.9 & 360 & 360 & 1400 & 1 \\
P1 & 200 & 7 & 360 & 1400 & 0.02 \\
P2 & 15.55 & 90 & 360 & 1400 & 0.25 \\
STATIC & - & - & - & - & - \\
\hline
\end{tabular}

atmospheric pressure (pulling liquids)(Varma \& Voldman, 2018).

On the other hand, there are further considerations regarding the tubbing employed on the connections of the system. For instance, a high permeability could enable gases to enter the system, or as another example, different temperatures among tubbing and device can produce a gradient of solubility of gases, which will come up as bubbles. On top of everything, bubbles not only can produce membrane damage(Varma \& Voldman, 2018) but also modify the illumination of the images taken, generating visual heterogeneity on the background, which could lead to inaccuracies in the image analysis. 


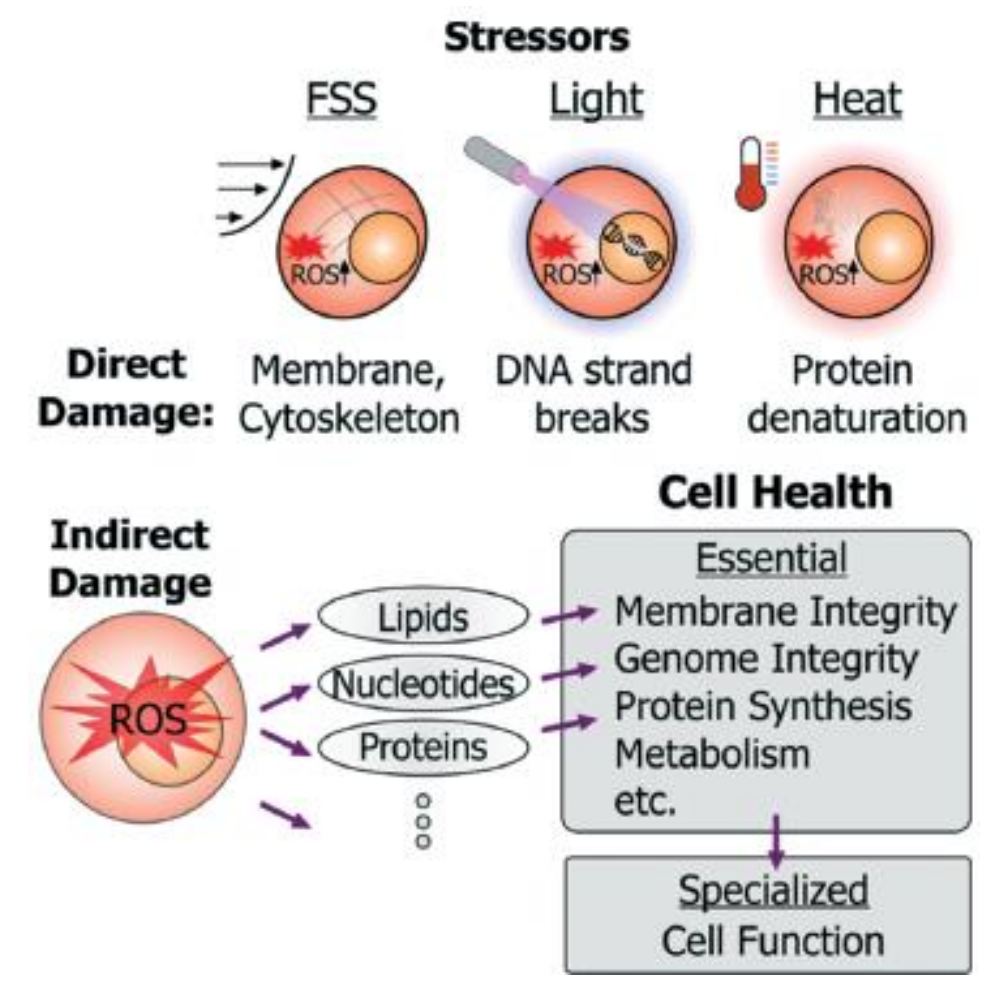

Figure 5. Examples of direct and indirect cell damage by microenvironment stressors(Varma \& Voldman, 2018). Certain stressors can produce early visible direct cell damage, in contrast, others can trigger complex biological cascades and affect cell health in an indirect form.

\section{Perfusion systems}

The prime objective of using perfusion techniques is to achieve a controlled and homogeneous environment(Griffiths, 1990). Nowadays, there are several strategies to perfuse cell cultures. Nevertheless, it does not mean that all of them suits to reach our goals. Consider the composition of the device is a crucial factor, as we mentioned before, working at a pressure above atmospheric pressure (pushing liquids) avoids bubble introduction through permeable devices that can occur when operating below atmospheric pressure (pulling liquids)(Varma \& Voldman, 2018). Additionally, the size and volume of the device to perfuse are also decisive. Commercially available pumps can manipulate from nanoliters to liters with different accuracy, that is why those features will give us a clue which could fit on the perfusion system. However, we will never have to forget about the specific requirements of the cell line employed and the purpose of the assay. 


\section{Peristaltic pumps}

Peristaltic pumps are based on positive displacement in which a flexible conduit is pressed to displace the liquid inside the conduit (Figure 6). As a consequence of this mechanism, the resultant flow is pulsatile and oscillatory in principle rather than constant(Byun et al., 2014). The typical industry standard for fill volume accuracy is $\pm 0.5 \%$. Peristaltic dispensing pumps meet this requirement for fill volumes as small as $0.5 \mathrm{ml}$. Below that fill volume, accuracy can be as good as $\pm 1 \%$ (Jørgensen \& Lambert, 2008). Furthermore, when utilizing peristaltic pumps, we must consider that the pinching mechanism of the pump can cause cellular damage(Byun et al., 2014).

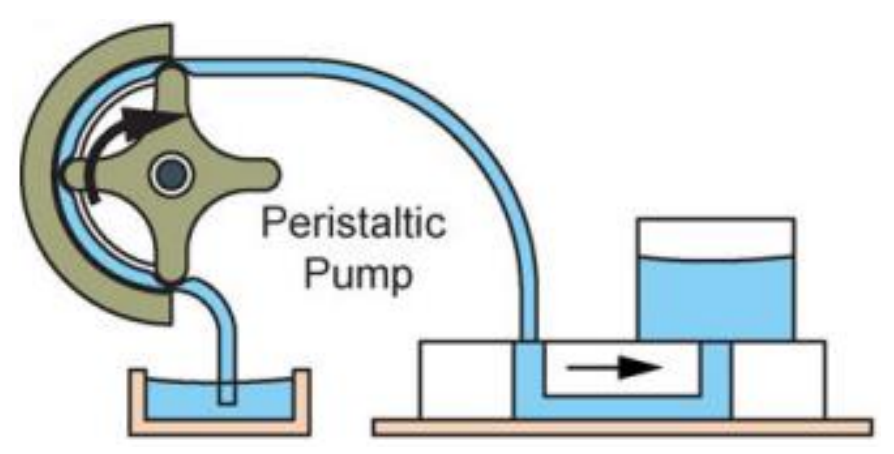

Figure 6. Peristaltic pump principle. A flexible tube is wrapped around a rotor that has rollers that press the tubing at different positions and as the rotor cam rotates liquid is pushed through the tube(Byun et al., 2014).

\section{Syringe pumps}

Syringe pumps are the first flow controller used in microfluidics. In a syringe pump, fluid is held in the reservoir of a syringe, and a moveable piston controls fluid delivery(FDA, n.d.)(Figure 7). The performance depends on its engine quality and the mechanical precision of its moving parts(Elveflow, n.d.-b)with an accuracy of \%5 according to international infusion pump standards(IEC 60601-2-24:2012, 2012; Weinger \& Kline, 2016). In other words, syringe pumps do not measure flow. Flow is calculated as a factor between the respective syringe scale and the constant of the minimum piston step. 
Consequently, it is necessary to consider the size of the syringe to avoid pulsatile flows and undesired effects. Small syringe sizes will increase the accuracy at low flow rates. Nevertheless, the volume will delimitate the assay.

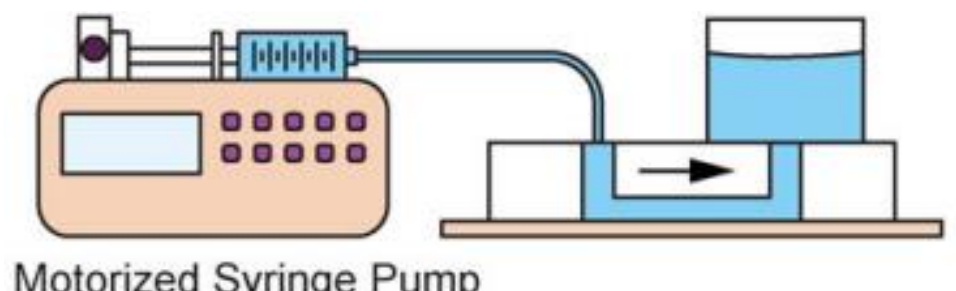

Figure 7. Motorized syringe pump principle. Syringe pumps use a piston to generate positive pressure to push liquids out of a liquid conduit(Byun et al., 2014).

\section{Microfluidic pumps}

Microfluidics is the science and technology of systems that process or manipulate small $\left(10^{-9}\right.$ to $\left.10^{-18} \mathrm{~L}\right)$ amounts of fluids, usually in channels with dimensions of tens to hundreds of micrometers(Whitesides, 2006). As an example, the Elveflow microfluidic systems (Elveflow, France) can handle fluids accurately from nanoliters up to milliliters and monitored with accuracy low to $5 \%$ of the measured value. The benefits of this system are the decreased response time and the pressure stability with a standard deviation of $0.005 \%$, resulting in a pulseless flow(Elveflow, n.d.-a).

The starter pack of the Elveflow microfluidic system (Elveflow, France) is a softwarecontrolled system capable of control and monitor the pressure or flow conditions on a microfluidic device (Figure 8)(Elveflow, n.d.-a).

\section{Live-cell imaging and Evaluation of Cell Health}

Novel technologies have been developed in the field of automated microscopes allowing the user to track cells accurately and for extended periods. These technologies include robotic stages, environmental chambers, and auto-focus methods. Therefore, cellular processes can be followed up over time, even in adjustable environments, allowing us to collect an increased amount of information about the cellular response under the selected circumstances. The main factor for live- 


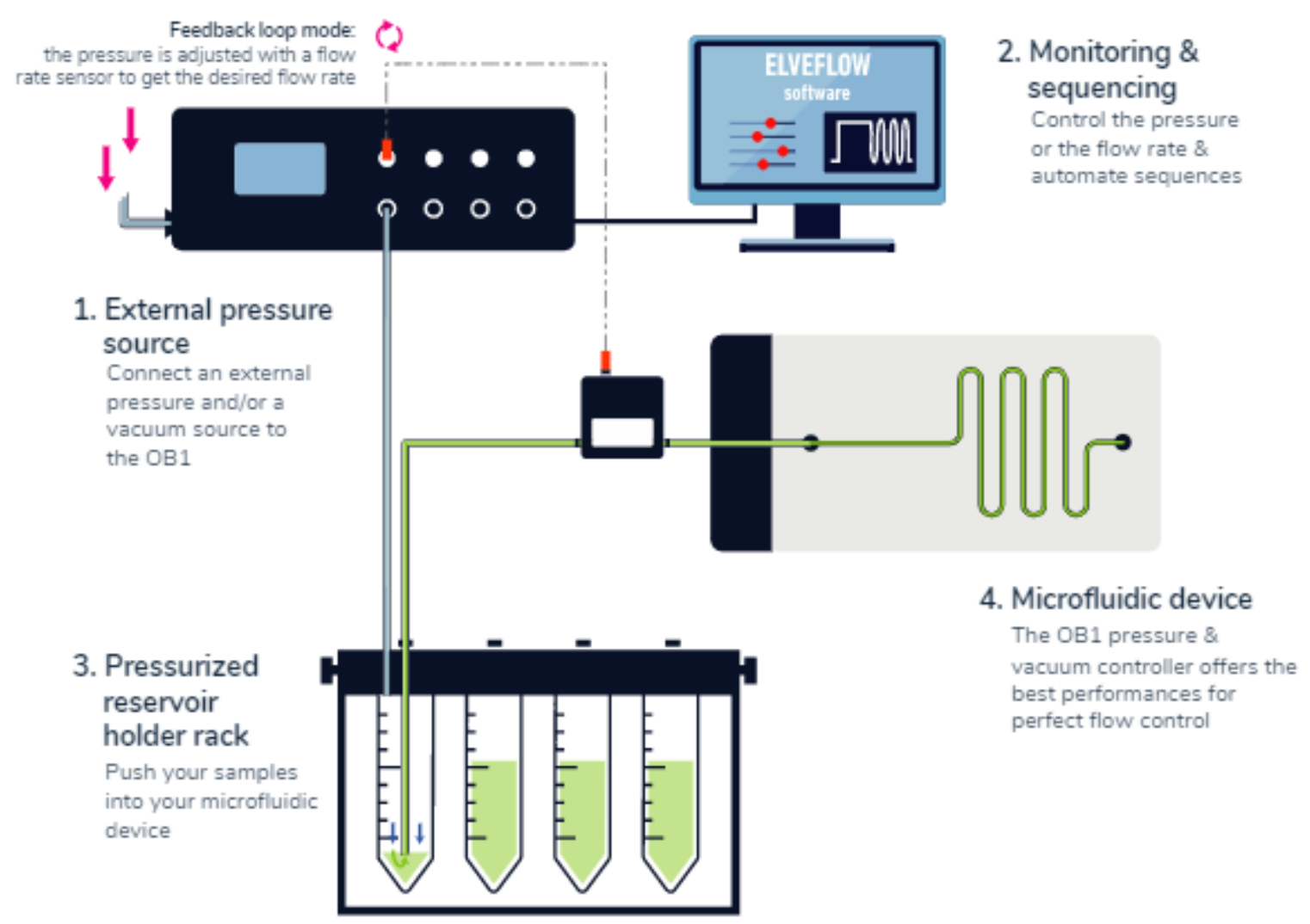

Figure 8. Diagram of Elveflow microfluidic system(Elveflow, n.d.-a).(1) OB1 Mk3 Pressure Controller connected to an external pressure source. The controller receives a feedback from OB1 MK3 Flow Controller. (2) The Elveflow software can monitor the conditions and communicate with the pressure controller. (3) The pressurized reservoir contains the samples ready to infuse (4) The manipulation of the conditions on the microfluidic device is the final goal.

cell imaging is to maintain cell viability. Monitored temperature, $\mathrm{CO}_{2}$ level, and humidity are crucial in any live-cell imaging experiment, thus environmental chambers and stage top incubators were developed to achieve optimal conditions (Figure 9)(Frigault et al., 2009; Ibidi GmbH, n.d.-b; Jensen, 2013).

Thankfully, time-lapse live imaging allows visualizing the dynamic behavior of cells over time(Chirieleison et al., 2011). Nowadays, it is possible to observe in high-quality cellular processes from seconds to weeks(Depaoli et al., 2019; Held \& Mongeon, 2019; Z. Liu et al., 2015) (Figure 10). Cellular response assays as calcium imaging that are fast as seconds still can be appreciated in real-time thanks to the combination of those different utilities on the modern microscopes(Desmet et al., 2017). 
However, to assess cell state in the device microenvironment, we have to consider the variety of assays used for assessing cell health (Figure 11)(Varma \& Voldman, 2018). Mainly, specific assays usually are destructive, costly, and complicated and hence technically prohibitive(Varma \& Voldman, 2018). In contrast, there are also other methods to asses cell health in a gross manner and, at the same time, preserve the cell cultures. However, it is necessary a correct sampling of the whole cell population to properly asses characteristics as viability or morphology. Several authors consider the trypan blue exclusion assay as the gold standard for cell viability on their projects ${ }^{48-50}$. The benefit of this technique is the quick assessment of cell number and viability. The continuous follow-up of the cell culture also enables us to detect proliferation visually. This image data could be utilized not only to analyze cell

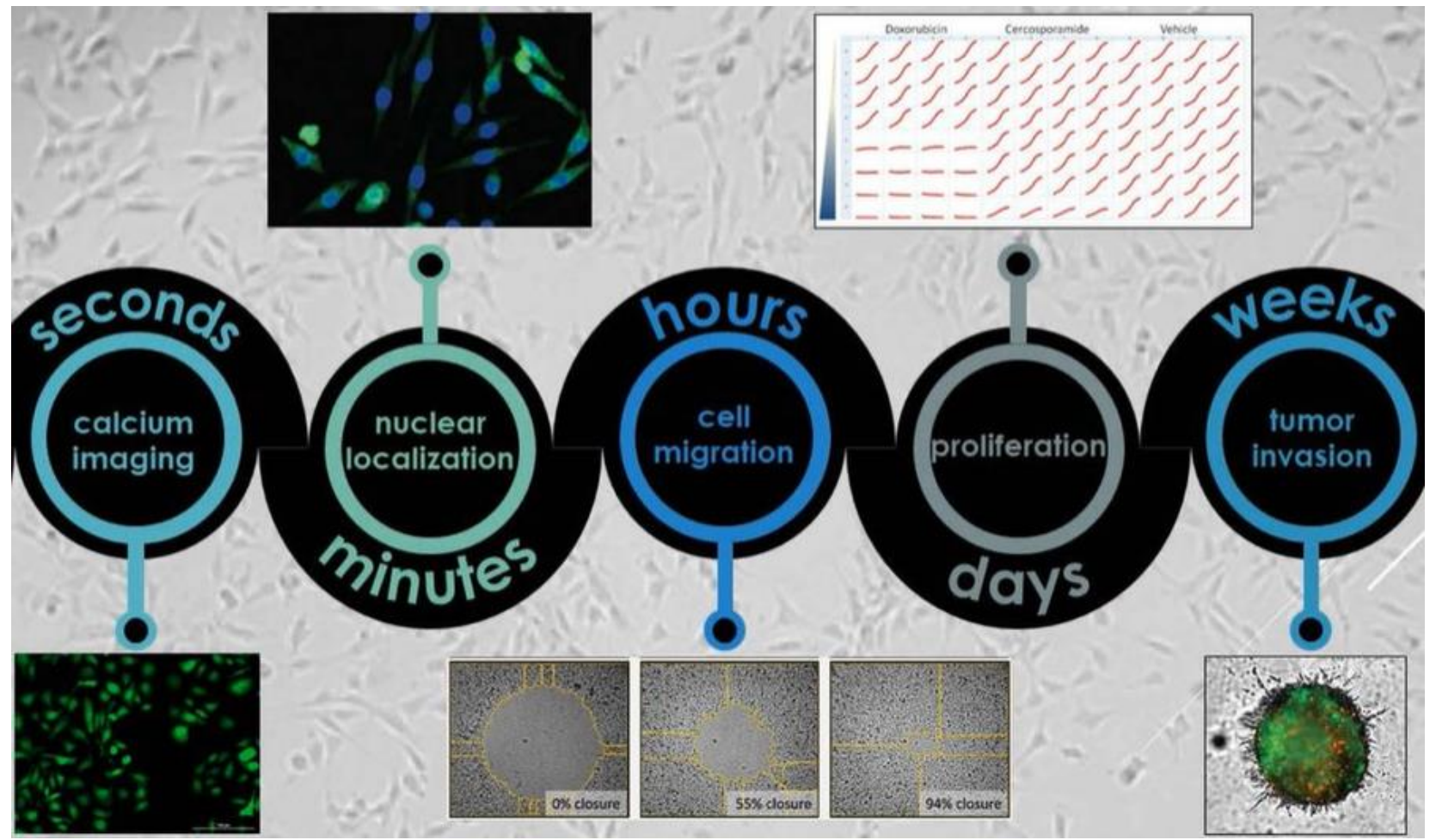

Figure 10. Examples of cellular response assays ${ }^{48}$. Several intracellular and cellular processes can be observed and therefore, with the appropriate strategy, quantified. 


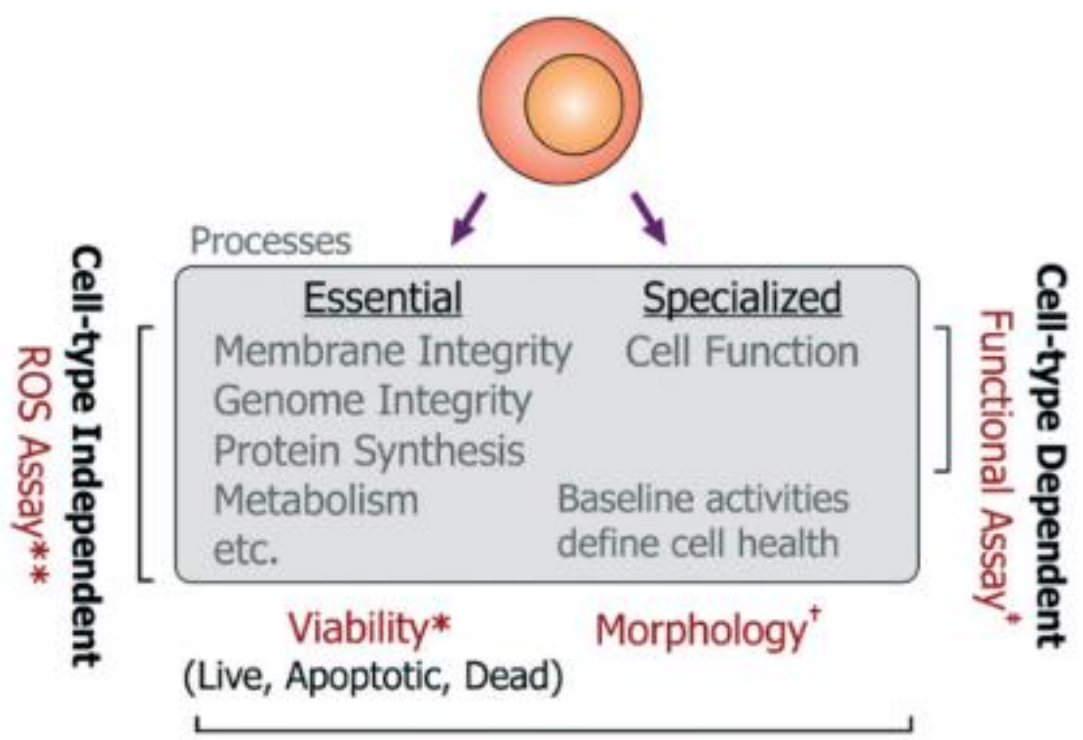

Gross Assessment

* Measure from immediately after to 1-2 days ( cell cycle)

**Measure immediately ${ }^{\dagger}$ Observe qualitatively ${ }^{*}$ Optional

Figure 11. Recommended assays for Cell Health(Varma \& Voldman, 2018). Several assays can be performed in order to assess healthy cells. Those methods can be categorized in cell type dependent or independent. Nevertheless, for a gross assessment it is possible to rely in viability and morphology measurements.

behavior but also to generate an image database for further applications. As an example, the database can be employed as training data for artificial intelligence algorithms and improve cell detection or single-cell tracking.

\section{Anticancer drugs}

For a long time, the standard drug screening was constrained to the analysis of the start and endpoints of established cell lines. However, the advances of the technology in high content imaging systems gave us a useful tool to obtain even more information about these time-lapse assays.

It is crucial to highlight toxicity and the restricted effectiveness of the anticancer agents. That is why the necessity of improving the capacity of drugs and therapies to fight against cancer cells without compromising the health condition of patients. On the other hand, Cancer is continuously adapting, as the tumor growths, new mutations appear, and populations of genetically distinct cells emerge (Figure 12)(Gerstung et al., 2017; Willyard, 2016). 
Currently, the new modality of drug administration metronomic chemotherapy has emerged to overcome the problems caused by the traditional chemotherapy regimens, toxicity, and therapeutic resistance. This regime is based on the frequent administration of conventional chemotherapeutic agents at low doses with the advantage of minimizing side effects and acquired drug resistance(Maiti, 2014).

The most widely used approach in cancer research is classical pharmacology, also known as phenotypic drug discovery, which relays on the in vitro assessment of anticancer activity. A phenotypic cancer approach is partially explained to a lack of an identified target in some cancers(Lage et al., 2018).

New high content automated methods can help us to have more robust results, increasing the number of experiments. Consequently, not only the development of modern strategies and drugs will be benefited but also facilitate the identification of different purposes on existing medications for new indications(Pantziarka et al., 2018).

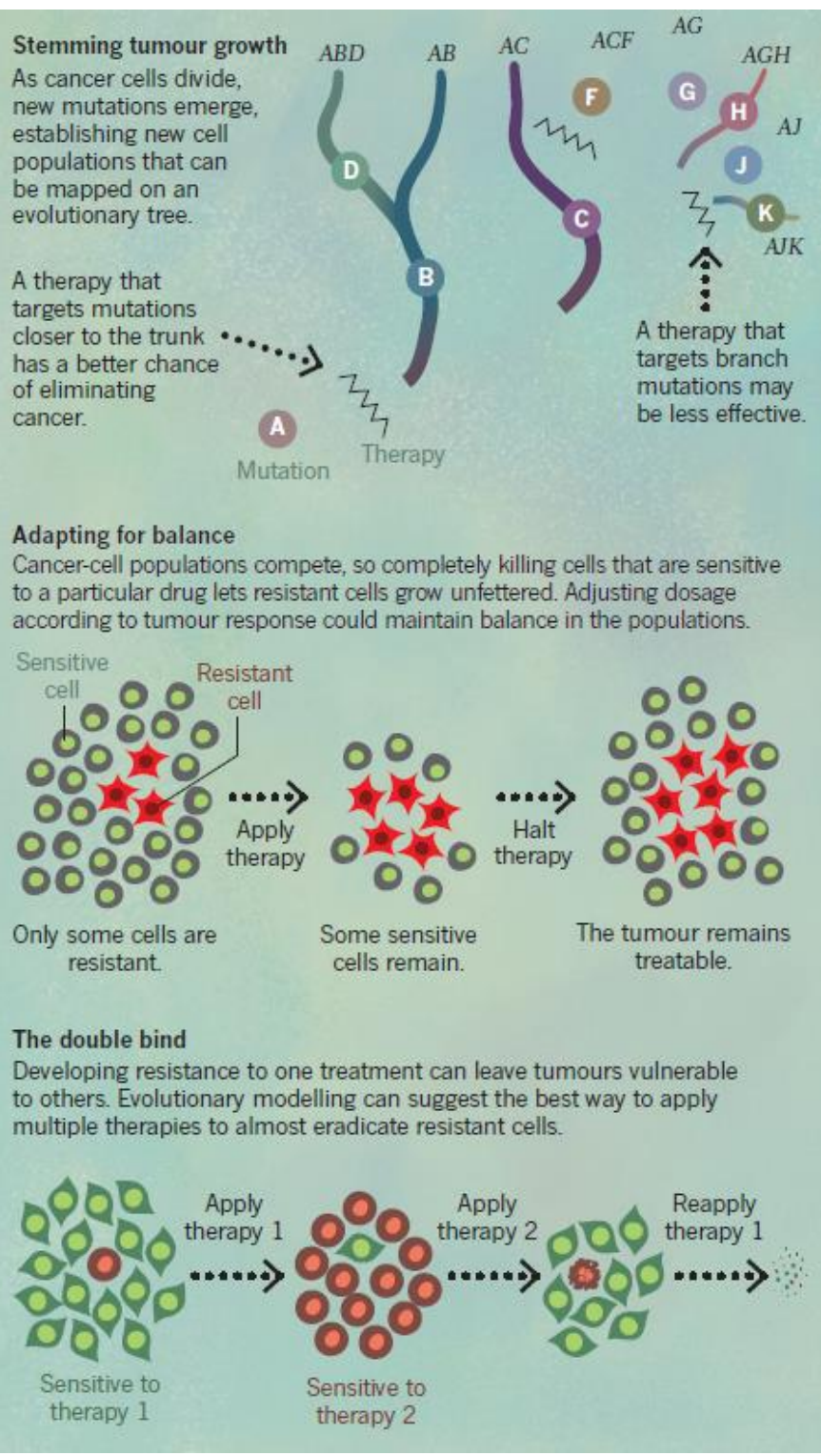

Figure 12. Evolving strategies(Willyard, 2016).

Oncologists are adapting cancer-treatment strategies to consider how a tumor evolves. 


\section{Breast Cancer}

Cancer is a generic term for a large group of diseases that can affect any part of the body. One defining feature of cancer is the rapid creation of abnormal cells that grow beyond their usual boundaries, and which can then invade adjoining parts of the body and spread to other organs, the latter process is referred to as metastasizing. Metastases are a significant cause of death from cancer(WHO, n.d.).

Cancer is a leading cause of death worldwide, accounting for an estimated 9.6 million deaths in 2018. Notably, breast cancer is the most common in women, holds the second position between the most common cancers with 2.09 million cases, and occupies the fifth position between the most commons causes of death by cancer with 627000 deaths (Figure 13)(Bray et al., 2018; WHO, n.d.).

Nowadays, we can define three major breast cancer subtypes: hormone receptorpositive/ERBB2 negative (HR+/ERBB2-), ERBB2 positive (ERBB2+), and triplenegative (Table 2)(Waks \& Winer, 2019).

Different therapeutic strategies and new anticancer drugs have been tested over the last years, to eradicate the tumor from the breast and lymph nodes to prevent metastasis, or in cases of metastatic breast cancer, mitigating symptoms and prolonging life. However, as we mentioned before, new methodologies can lead us to more robust and precise results, decreasing the developed resistance to widely known therapies, and establishing new ones. Therefore, as first steps, we investigated the behavior of breast cancer cell lines in our system, aiming to:

$\checkmark$ Develop an automated perfusion system for long-term live cell culture imaging.

$\checkmark$ Validate the system with a breast cancer cell line.

$\checkmark$ Determine and characterize the cell growth of a breast cancer cell line under different perfusion strategies.

$\checkmark$ Evaluate the most appropriate perfusion strategy for media delivery. 


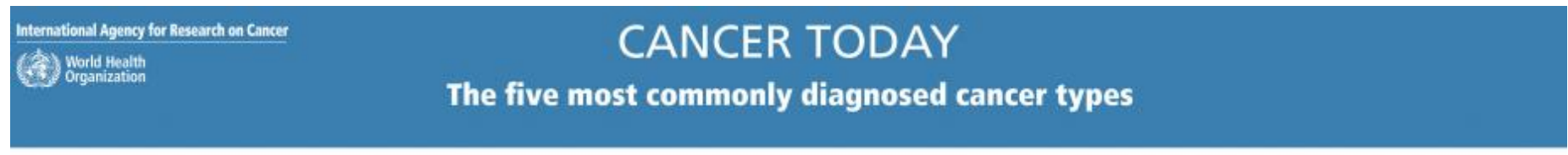

Percentages of new cancer cases and cancer deaths worldwide in 2018

\section{Incidence}

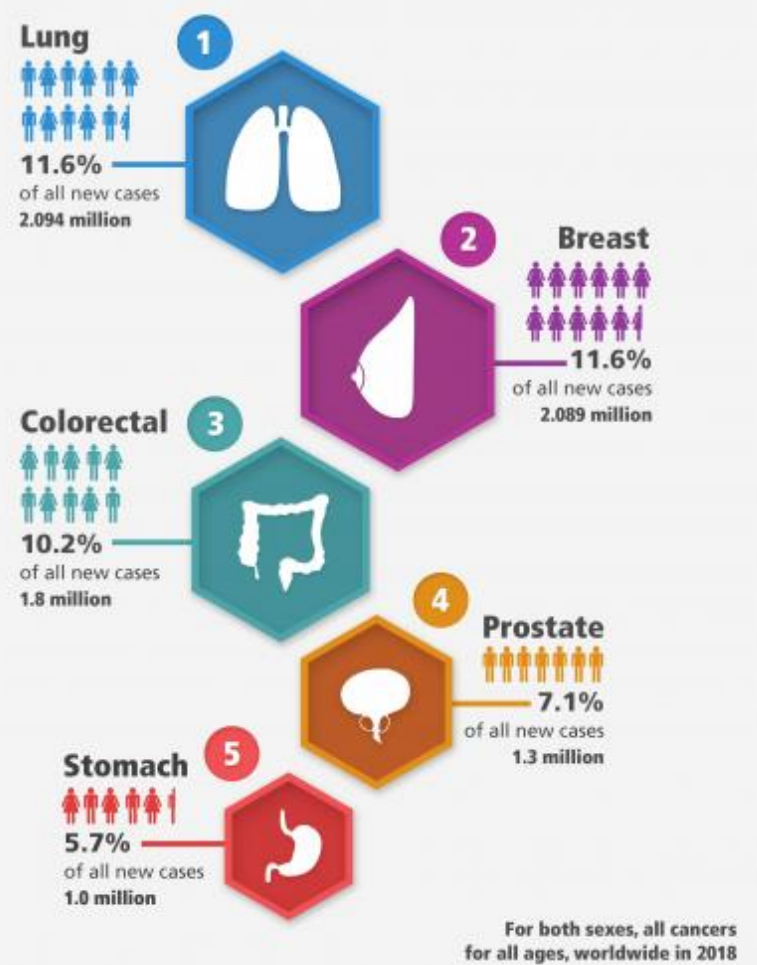

\section{Mortality}

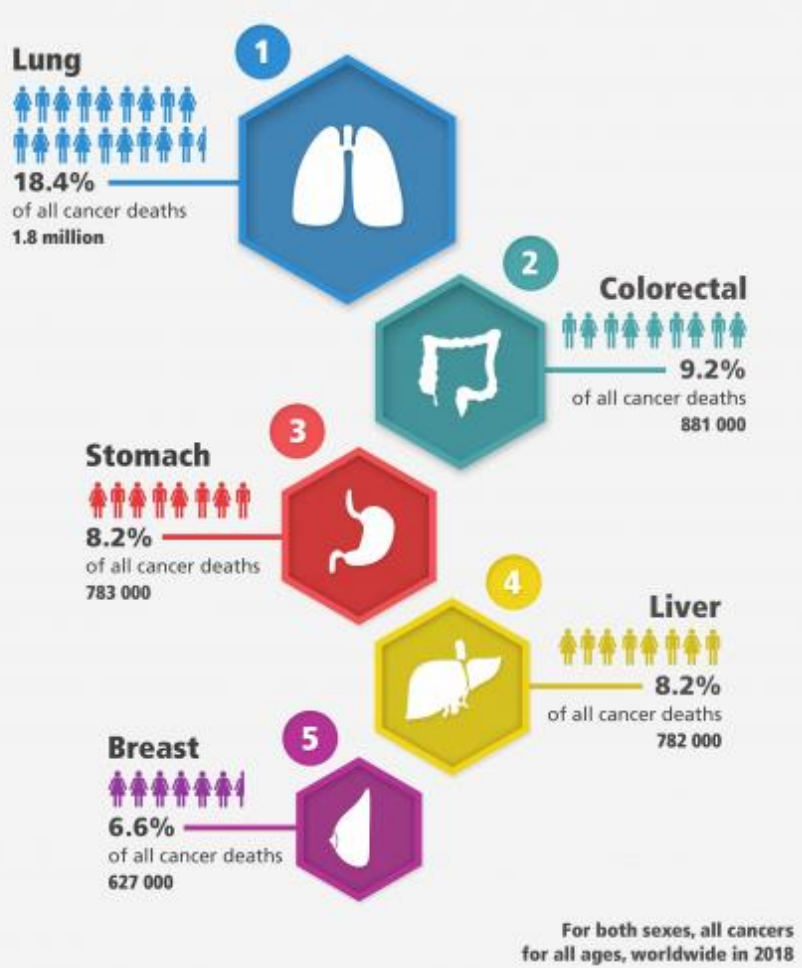

\section{Females}

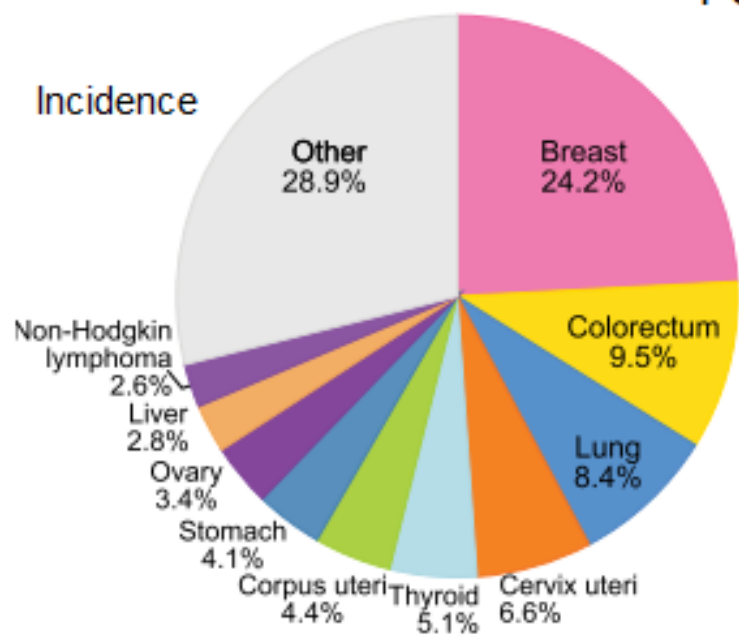

8.6 million new cases

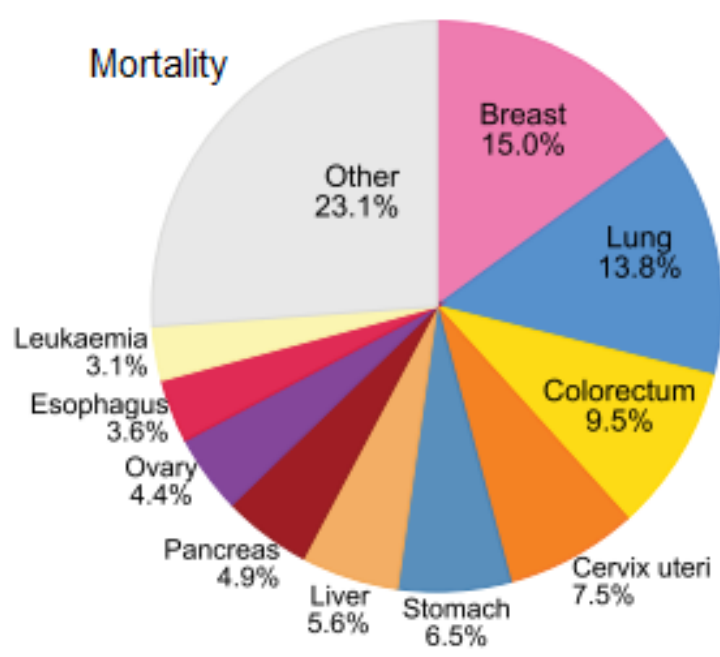

4.2 million deaths

Figure 13: Percentages of new cancer cases and cancer deaths worldwide in 2018(Bray et al., 2018). In both sexes combined, lung cancer still the most diagnosed and the leading cause of cancer death. However, analyzing in detail, females breast cancer has the highest incidence and mortality in females with $24.2 \%$ and $15 \%$, respectively. 
Table 2. Therapeutic options for the 3 breast cancer subtypes(Waks \& Winer,

\begin{tabular}{|c|c|c|c|}
\hline & HR+ / ERBB2- & ERBB2+ (HR+ or HR- $)$ & Triple-Negative \\
\hline $\begin{array}{l}\text { Pathological } \\
\text { definition }\end{array}$ & $\begin{array}{l}\geq 1 \% \text { of tumor cell stain } \\
\text { positive for estrogen } \\
\text { receptor or } \\
\text { progesterone receptor } \\
\text { proteins }\end{array}$ & $\begin{array}{l}\text { Tumor cells stain strongly } \\
(3+) \text { for ERBB2 protein, or } \\
\text { the ERBB2 gene is } \\
\text { amplified in tumor cells. } \\
\text { Approximately half of the } \\
\text { ERBB2+ tumors are also } \\
\text { HR+ }\end{array}$ & $\begin{array}{l}\text { Tumor does not } \\
\text { meet any pathologic } \\
\text { criteria for positivity } \\
\text { of the estrogen } \\
\text { receptor, } \\
\text { progesterone } \\
\text { receptor, or ERBB2. }\end{array}$ \\
\hline $\begin{array}{l}\text { Molecular } \\
\text { pathogenesis }\end{array}$ & $\begin{array}{l}\text { Estrogen receptor a (a } \\
\text { steroid hormone } \\
\text { receptor) activates } \\
\text { oncogenic growth } \\
\text { pathways }\end{array}$ & $\begin{array}{l}\text { The oncogene ERBB2, } \\
\text { encoding ERBB2 receptor } \\
\text { tyrosine kinase from the } \\
\text { epidermal growth factor } \\
\text { receptor family is } \\
\text { overactive }\end{array}$ & $\begin{array}{l}\text { Unknown (likely } \\
\text { various) }\end{array}$ \\
\hline $\begin{array}{l}\text { Typical } \\
\text { systemic } \\
\text { therapies for } \\
\text { non- } \\
\text { metastatic } \\
\text { disease } \\
\text { (agents, } \\
\text { route, } \\
\text { and duration) }\end{array}$ & $\begin{array}{l}\text { Endocrine therapy (all } \\
\text { patients): } \\
\text { - Tamoxifen, letrozole, } \\
\text { anastrozole, or } \\
\text { exemestane } \\
\text { - Oral therapy } \\
\text { - 5-10 years } \\
\text { Chemotherapy (some } \\
\text { patients): } \\
\text { - Adriamycin } \\
\text { /cyclophosphamide (AC) } \\
\text { - Adriamycin } \\
\text { /cyclophosphamide/ } \\
\text { paclitaxel (AC-T) } \\
\text { - Docetaxel } \\
\text { /cyclophosphamide (TC) } \\
\text { - Intravenous therapy } \\
\text { - 12-20 weeks }\end{array}$ & $\begin{array}{l}\text { Chemotherapy plus } \\
\text { ERBB2-targeted therapy } \\
\text { (all patients): } \\
\text { - Paclitaxel/trastuzumab } \\
\text { (TH) } \\
\text { - Adriamycin/ } \\
\text { cyclophosphamide/ } \\
\text { paclitaxel/trastuzumab } \\
\pm \text { pertuzumab (AC-TH } \pm P \text { ) } \\
\text { - Docetaxel /carboplatin } \\
\text { /trastuzumab } \pm \\
\text { pertuzumab (TCH } \pm \text { P) } \\
\text { - Intravenous therapy } \\
\text { - } 12-20 \text { weeks of } \\
\text { chemotherapy; } 1 \text { year of } \\
\text { ERBB2-targeted therapy } \\
\text { Endocrine therapy (only } \\
\text { HR+) } \\
\text { - Tamoxifen, letrozole, } \\
\text { anastrozole, or } \\
\text { exemestane } \\
\text { - Oral therapy } \\
\text { - } 5-10 \text { years }\end{array}$ & $\begin{array}{l}\text { Chemotherapy (all } \\
\text { patients): } \\
\text { - AC } \\
\text { - AC-T } \\
\text { - TC } \\
\text { - Intravenous } \\
\text { therapy } \\
\text { - } 12-20 \text { weeks }\end{array}$ \\
\hline
\end{tabular}




\section{Materials and Methods}

\section{Cell lines}

\section{JIMT-1}

The breast cancer cell line JIMT-1 (HER2-enriched, ER', PR', HER2 ${ }^{+}$, ACC 589)(Leibniz Institute German Collection of Microorganisms and Cell Cultures, Germany) has been cultivated using Dulbecco's Modified Eagle Media DMEM (Gibco Thermo Fisher Scientific, USA). The media was supplemented with $10 \%$ fetal bovine serum (Gibco Thermo Fisher Scientific, USA) and 1\% Penicillin-Streptomycin 10,000 U/ml (Gibco Thermo Fisher Scientific, USA). This adherent cell line was incubated on Heracell 150i (Thermo Fisher Scientific, USA) at $37^{\circ} \mathrm{C}$ in a humidified atmosphere containing $5 \%$ $\mathrm{CO}_{2}$ and passaged to a new flask containing fresh media every three to four days, depending on their concentration.

\section{MCF-7}

The breast cancer cell lines MCF-7 (Luminal A, ER ${ }^{+}, \mathrm{PR}^{+/-}, \mathrm{HER} 2^{-}$, ACC 115)(Leibniz Institute German Collection of Microorganisms and Cell Cultures, Germany) has been cultivated using Dulbecco's Modified Eagle Media DMEM (Gibco Thermo Fisher Scientific, USA). The media was supplemented with $10 \%$ fetal bovine serum (Gibco Thermo Fisher Scientific, USA) and 1\% Penicillin-Streptomycin 10,000 U/ml (Gibco Thermo Fisher Scientific, USA). This adherent cell line was incubated on Heracell 150i (Thermo Fisher Scientific, USA) at $37^{\circ} \mathrm{C}$ in a humidified atmosphere containing $5 \%$ $\mathrm{CO}_{2}$ and passaged to a new flask containing fresh media every three to four days, depending on their concentration. 


\section{Cell culture vessels}

\section{Ibidi $\mu$-Slide 4 Well ibiTreat.}

The open $\mu$-Slide 4 Well Chip (Ibidi, Germany) has four independent wells and a tightly fitting lid (Figure 14)(Ibidi GmbH, n.d.-a). Each well has a working volume of $700 \mu \mathrm{L}$, and the total volume of the well is approximately $1000 \mu \mathrm{L}$ without generating spillover. The ibiTreat is a physical surface modification that makes it hydrophilic and adhesive to virtually all cell types. Moreover, this surface allows analysis under perfusion conditions.

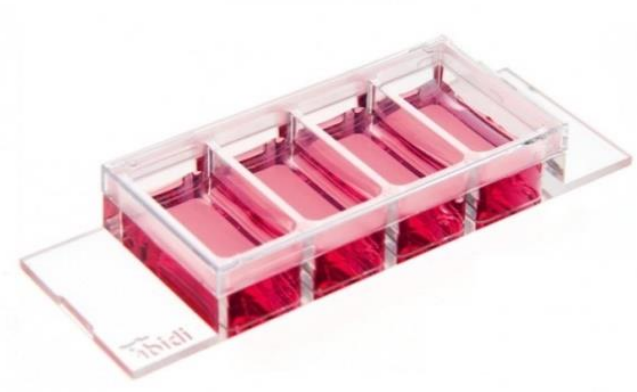

Figure 14. Design of an Ibidi $\mu$-Slide 4 Well chip(Ibidi GmbH, n.d.-a).

\section{Ibidi $\mu$-Slide 4 Well Ph+ ibiTreat}

The open $\mu$-Slide 4 Well Ph+ Chip (Ibidi, Germany) has four independent wells with an intermediate plate, it avoids meniscus formation and has a tightly fitting lid (Figure 15)(Ibidi $\mathrm{GmbH}$, n.d.-a). The chip is optimized for phase-contrast microscopy. Each well has a volume of $700 \mu \mathrm{L}$ above the intermediate plate, and the total volume of the well is approximately $1000 \mu \mathrm{L}$ without generating spillover. The ibiTreat is a physical surface modification that makes it hydrophilic and adhesive to virtually all cell types. Moreover, this surface allows analysis under perfusion conditions. 

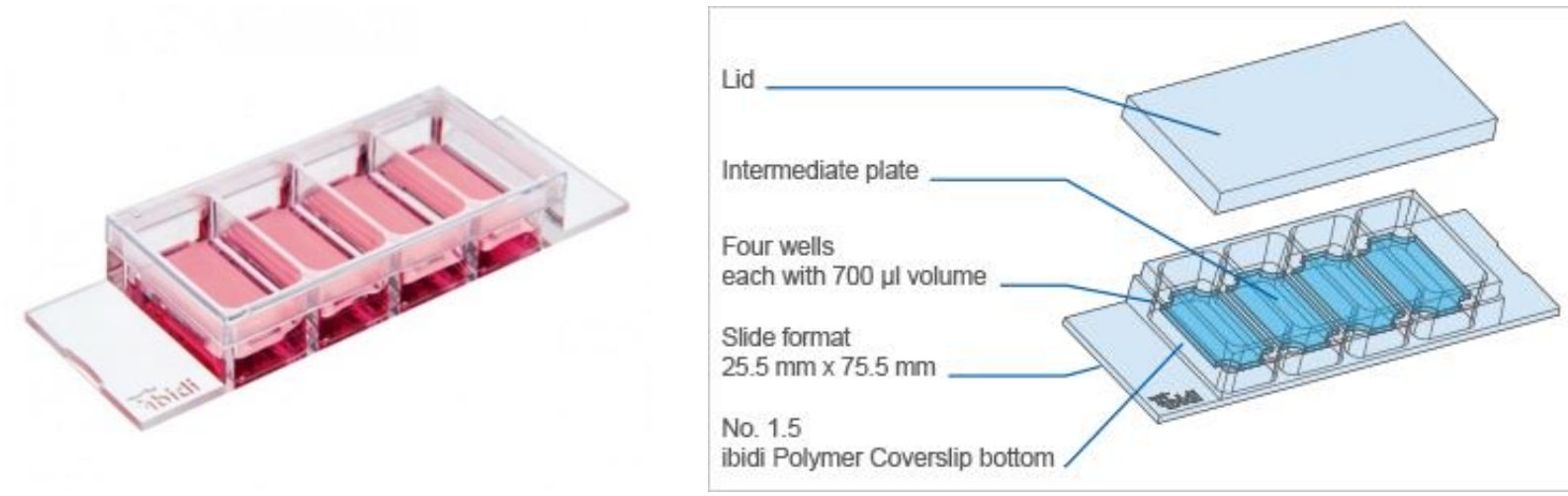

Figure 15. Design of an Ibidi $\mu$-Slide $4 \mathrm{Well} \mathbf{P h}+\mathrm{chip}$ (Ibidi GmbH, n.d.-a).

\section{Cell culture}

JIMT- 1 and MCF-7 cells were seeded on IBIDI $\mu$-Slide 4 Well and IBIDI $\mu$-Slide 4 Well $\mathrm{Ph}+$ in sterile conditions. In the case of the IBIDI $\mu$-Slide 4 well, $700 \mu \mathrm{L}$ of the cell suspension at a concentration of $1 \times 10^{5}$ were applied to each well, the slide was covered and placed inside the Lionheart FX. Furthermore, regarding IBIDI $\mu$-Slide 4 Well $\mathrm{Ph}+$, the procedure was similar but with the difference of injecting the cell suspension through one of the intermediate plate openings in the upper-right corner.

\section{Microscopes}

\section{Zeiss Axio Observer Inverted}

The inverted microscope Zeiss Axio Observer (Zeiss, Germany) has been complemented with the Incubator P S compact (Pecon, Germany), the $\mathrm{CO}_{2}$ Module S (Pecon, Germany) and the Heating Device Humidity S (Pecon, Germany). This environmental chamber allows adjusting temperature to $37^{\circ} \mathrm{C}, \mathrm{CO}_{2}$ levels to $5 \%$, and humidity up to $80 \%$ (Figure 16 )(MIAP, n.d.). Images were taken using magnification objectives Zeiss EC Plan-Neofluar 10x/0.3 and 40x/0.7. 


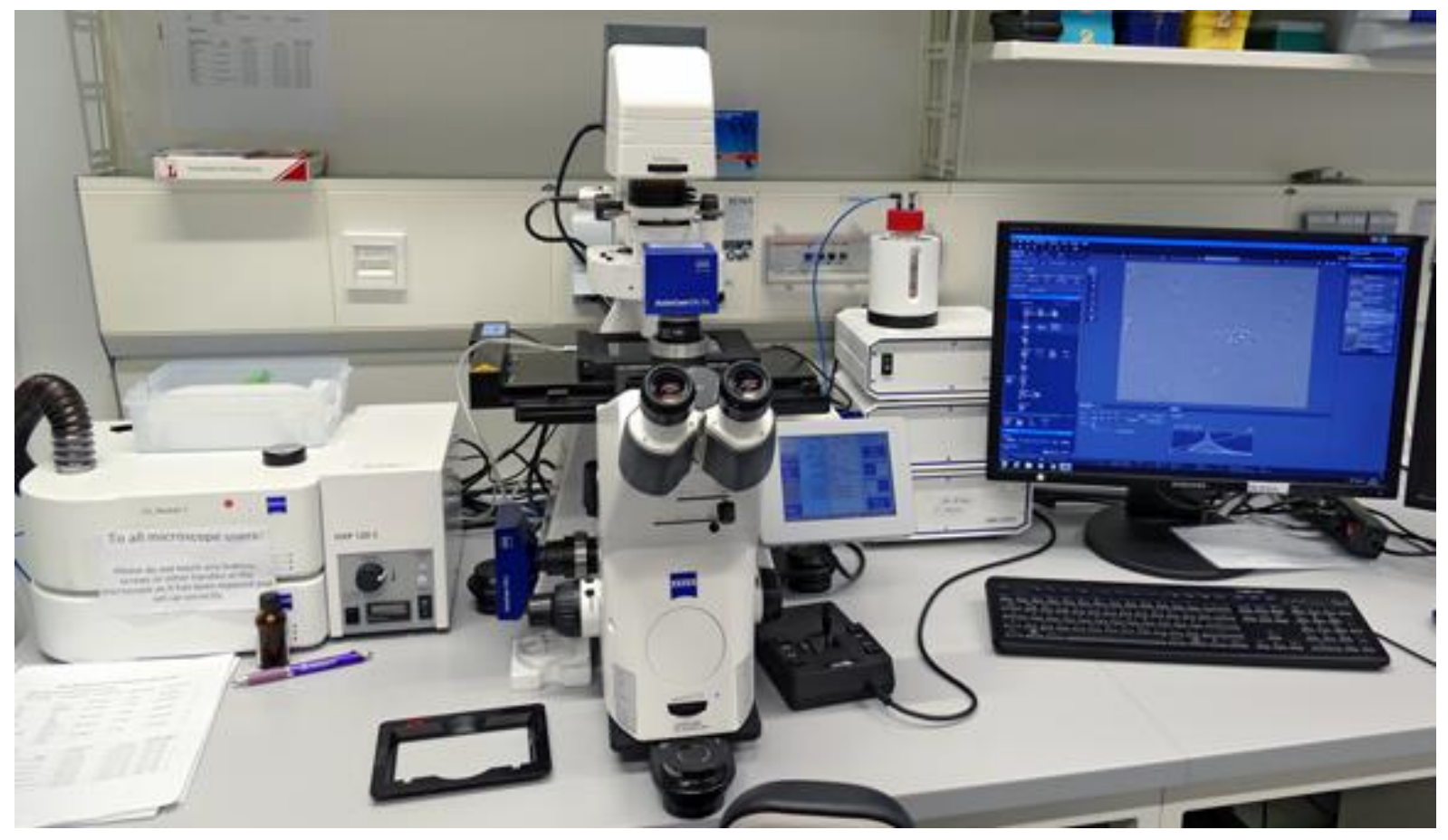

Figure 16. Zeiss Axio Observer Inverted Microscope(MIAP, n.d.).

Lionheart $F x$

The automated microscope Lionheart Fx (BioTek, USA) is a compact $(46.5 \mathrm{~cm} \times 45.5$ $\mathrm{cm} \times 35.8 \mathrm{~cm}$ ), inclusive microscopy system for a broad range of imaging workflows. This device counts with an environmental control cover (Figure 17)(BioSPX, n.d.). The temperature was set at $37^{\circ} \mathrm{C}$ and the $\mathrm{CO}_{2}$ adjusted at $5 \%$. Seven Petri dishes of 60

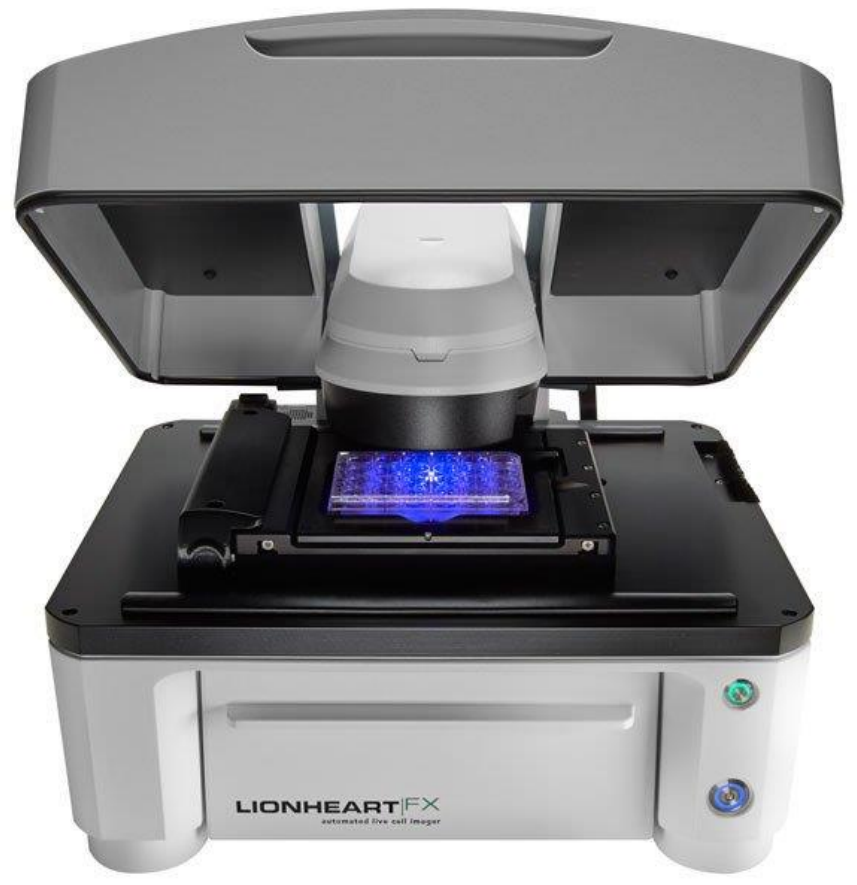

Figure 17. Lionheart ${ }^{\mathrm{TM}}$ FX Automated Microscope(BioSPX, n.d.). 
$\mathrm{mm} \times 15 \mathrm{~mm}$ filled with water were placed inside the incubator to increase the humidity of the environment, up to $70 \%$ with an average of $58 \%$. Images were taken using phase objective 20x Plan Fluorite WD 6.7 NA 0.45.

\section{Perfusion system}

\section{Adox AcTIVA A22 Syringe Pump}

The Adox AcTIVA A22 Syringe Pump (Adox, Argentine) is a precise programmable syringe pump, and it has a communications port to connect to a computer (Figure 18)(Adox, n.d.).

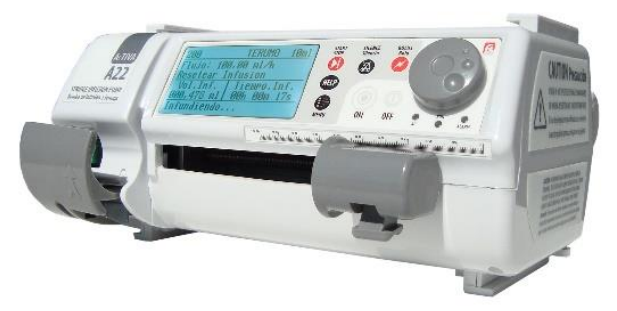

Figure 18. The Adox AcTIVA A22 syringe pump(Adox, n.d.).

Jecod DP-4

The Jecod DP-4 (Jecod Co Ltd, China) is a programmable peristaltic aquarium pump with four channels (Figure 19)(Jecod, n.d.).

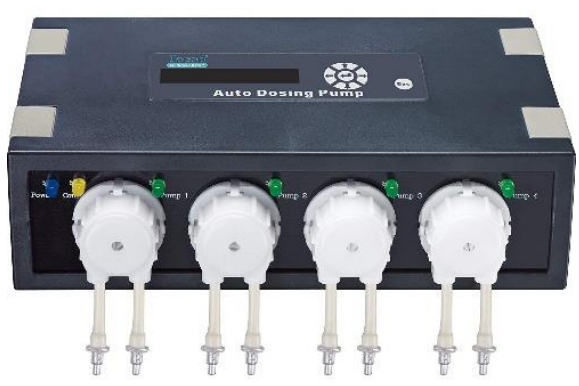

Figure 19. The Jecod DP-4 peristaltic

numn(larnd n a ) 


\section{Live-imaging}

Perfused systems could be a complex system of tubing, connectors, device, and bubble trappers. Although most cell culture microdevices are for single-use, one may need to disconnect and connect tubing during experimentation. Accordingly, it is beneficial to prevent contamination to form the connections always in a sterile environment(Varma \& Voldman, 2018).

Moreover, the need for tracking by microscopy can become a stressor in microsystems. Naturally, most cells in vivo are not exposed to light. We do not have to forget that infrared radiations produce heat transference without contact, and heating cells over physiological conditions will lead to abnormal responses. This issue will increase when fluorescence microscopy is necessary. In order to overcome this situation, lower intensities of the light source, shorter exposure time, and the use of long excitation wavelengths in the case where fluorescence is needed must be promoted(Frigault et al., 2009; Magidson \& Khodjakov, 2013; Varma \& Voldman, 2018).

Additionally, following the manufacturer instructions, the recommended observation area has been done in a proper distance from the walls, comparable to the channel height(Ibidi $\mathrm{GmbH}$, 2016). Three beacons equally distributed have been chosen to capture the images every 15 minutes (Figure 20) during six and four days for longterm experiments and over two days for short-term experiments.

Furthermore, after multiple observations to obtain image homogeneity, the intensity of the led was fixed at 10 , integration time $=100$, and gain=7.9. The focus strategy chosen was user-trainable autofocus. In this setting, the combination of manual

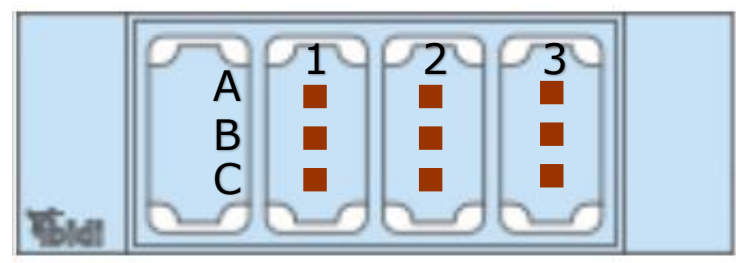

Figure 20. Diagram of beacons on IBIDI $\mu$-Slide 4 Well Ph+ chip(Ibidi $\mathrm{GmbH}$, n.d.-a). The left well only contains media as evaporation control, the next one (1) is a cell culture in static conditions as a positive control of proliferation and the other two ( 2 and 3 ) run the assay on the conditions to test. 
adjustment of the focus on a few sample wells and the correct height of bottom elevation is enough to train the system to select the best plane for imaging.

\section{Cell counting}

First, to recover the cells from the IBIDI $\mu$-Slide 4 Well $\mathrm{Ph}+$ chip, the media was removed manually using a pipet under sterile conditions. Next, washed twice with 700 $\mu \mathrm{L}$ of PBS and immediately $350 \mu \mathrm{L}$ of Trypsin-EDTA $0,25 \%$ (Gibco Thermo Fisher Scientific, USA) was added. The chip was placed inside the incubator for over three minutes. Afterward, $350 \mu \mathrm{L}$ of cDMEM was added to each well to stop trypsin and quickly proceed with trypan blue protocol for cell counting and viability assessing on the Bio-Rad TC10 ${ }^{\mathrm{TM}}$ (Bio-Rad, USA) automated cell counter. The fold-change was calculated as "Average fc: Cell count f/Cell count $i$ " where "Cell count $i$ " is the concentration of the cell suspension at the initial state, and "Cell count $f$ " is the concentration of Cells after trypsinization at the end of the experiment.

\section{Image Analysis}

Image series were analyzed applying a plugin from Fiji(Schindelin et al., 2012) named Trainable Weka Segmentation(Arganda-Carreras et al., 2017), and an algorithm developed by our colleague Dennis Raith(Raith, 2019) for adherent cells. The cell growth was calculated as the fold change applying the following equation: "Average Img fc: Area f/Area i" where "Area f" is the area covered by cells measured at the end of the experiment and "Area $\mathrm{i}$ " at the beginning.

\section{Trainable Weka Segmentation}

The Trainable Weka Segmentation is a Fiji(Schindelin et al., 2012) plugin that combines machine learning algorithms with a set of selected image features to produce pixel-based segmentation(Arganda-Carreras et al., 2017). A classifier model was trained with two classes, cell and background, on default settings with a selection 
of images obtained during the long-term experiments. Those images were selected with the following criteria: one image after two hours of seeding when the illumination is homogeneous on the sample and the cells are on suspension, one image where the cells are mostly attached at time $=8$ hours and, one image at time $=48$ hours where we can observe attached cells, debris and cells on division. Subsequently, a modified BeanShell script to apply the classifier to all images in a folder(ImageJ, n.d.) was applied. This script was modified to retrieve the measurement of the cell area in the segmented images of the dataset. The classifier model and the modified BeanShell are available, and both can be required by mail to the author.

\section{Deep Learning Algorithm}

A deep learning algorithm was developed by our colleague Dennis Raith to extract features from biological experiments(Raith, 2019). The dataset also was analyzed by him, retrieving measurements of the cell area. The algorithm was used as cited on "Exploration of Reinforcement Learning for Vision-based Automated Perfusion Systems" master thesis by Dennis Raith(Raith, 2019). Those values were compared with the analysis achieved by the Trainable Weka Segmentation.

\section{Data Analysis and Visualization}

Data were annotated in Microsoft Excel (Microsoft, USA), further on analyzed and plotted using Prism (GraphPad Software Inc, USA). Statistical analysis was done on Prism (GraphPad Software Inc, USA). Linear or exponential fits were obtained using Prism (GraphPad Software Inc, USA). Fit accuracy is expressed as the coefficient of determination (R2). 


\section{Results and discussion}

Considering the experience earned in the application of microdevices for suspension cells(Olmos et al., 2020), this project employed adherent cells on commercial chips for practical reasons. The Lionheart Fx proved to be more suitable than Zeiss Axio Observer Inverted in our experiments for being more accurate for monitoring several positions.

\section{Ibidi $\mu$-Slide 4 Well ibiTreat}

To achieve a setup not only distinguished by image quality but also for being coupled to a perfusion system commercial Ibidi $\mu$-Slide 4 Well ibiTreat chips were tested. Two strategies have been applied to connect the chip. On the first approach, inlet and outlet were drilled on the superior lid. Consecutively, the outlet was modified, and the lateral wall was drilled in order to maintain a certain level of media on the well (Figure 21). In both cases, always under sterile conditions.

Finally, the microdevice was connected with stainless steel catheter couplers 22ga $\mathrm{x}$ $15 \mathrm{~mm}$ (Instech Laboratories Inc, USA) through PU tubing, medical-grade, 3Fr, 0.025x.040in (Instech Laboratories Inc, USA). The Adox AcTIVA A22 Syringe Pump was employed to infuse the new media. A syringe Injeckt (B.Braun, Germany) of the necessary volume of media for the whole experiment plus a Luer stub, $22 \mathrm{ga} \times 0.25 \mathrm{in}$ (Instech Laboratories Inc, USA) were necessary to connect to the chip appropriately. On the other hand, the peristaltic pump Jecod DP-4 was utilized for draining the old media. The old media was collected in a falcon tube due to a microfluidic lid adapter (Elveflow, France) to assure cells are not being drained. However, meniscus formation on the chip impairs control of the total volume generating whether spillover or dry of the well. For this reason, this device is not suitable for our objectives.
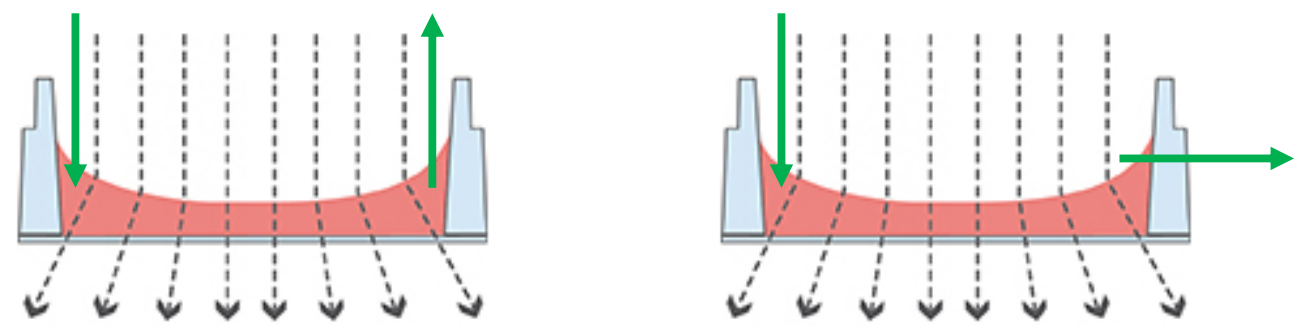

Figure 21. Strategies to perfuse the Ibidi $\mu$-Slide 4 Well chip. The green arrows indicate the steel couplers and the flow of the media. In this diagram is possible to detect the meniscus formation. The black arrows shows the perturbing effect of the meniscus on the light path(Ibidi GmbH, n.d.-a). 


\section{Ibidi $\mu$-Slide 4 Well Ph+ ibiTreat}

Fortunately, Ibidi has developed an option. The Ibidi $\mu$-Slide 4 Well $\mathrm{Ph}+$ chip avoids meniscus formation and its optimized for phase contrast microscopy(Ibidi GmbH, n.d.a).

Long-term live-cell imaging has been performed for a period of up to six days in static conditions to asses cellular growth at standard conditions of temperature, humidity, and $\mathrm{CO}_{2}$ on Lionheart FX (Figure 22). Static conditions mean that the media was renewed every two days manually. The protocol of adherent cell count was implemented, but we were unable to perform image analysis due to the high confluence at the endpoint, ratifying the necessity of briefer experiments. The observation of the time-lapses confirmed the requirement of experiments shorter than 108 hours. The experiment was repeated over four days. In parallel, we tested the cellular growth inside a traditional incubator with a humidity of $99 \%$. A significant difference has been found on the values for cell count but not for viability (Figure 23), Welch's t-test has been performed on GraphPad Prism retrieving a $\mathrm{p}$ value $=0.0149$ and an $r 2=0.8670$, which expose the importance of the humidity levels on cell growth.

Intending to maximize the number of experiments without overlooking the objectives and keeping in mind that the overall doubling time for the cell lines chosen is between
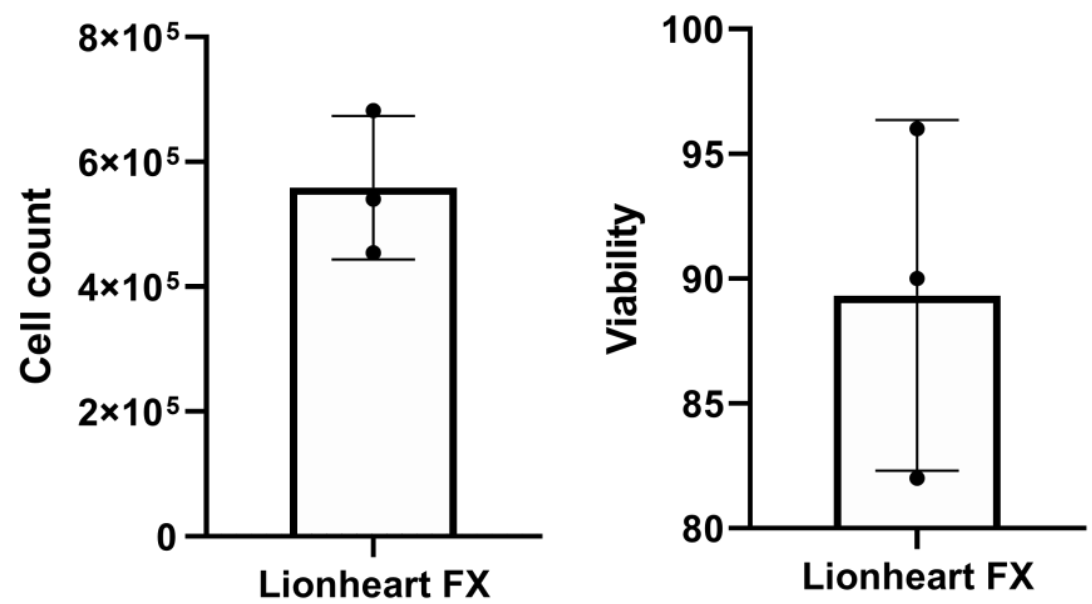

Figure 22. Long-term cell culture of JIMT-1 at static conditions on IBIDI $\mu$-Slide 4 Well Ph+ chip in Lionheart FX. After six days of cell culture with manual renewal of media the JIMT-1 cell line almost sextuplicate the cell number and maintain a viability close to $90 \%$. 
30 and 40 hours, the extension of the perfused experiments has been set to 48 hours since cells are seeded.
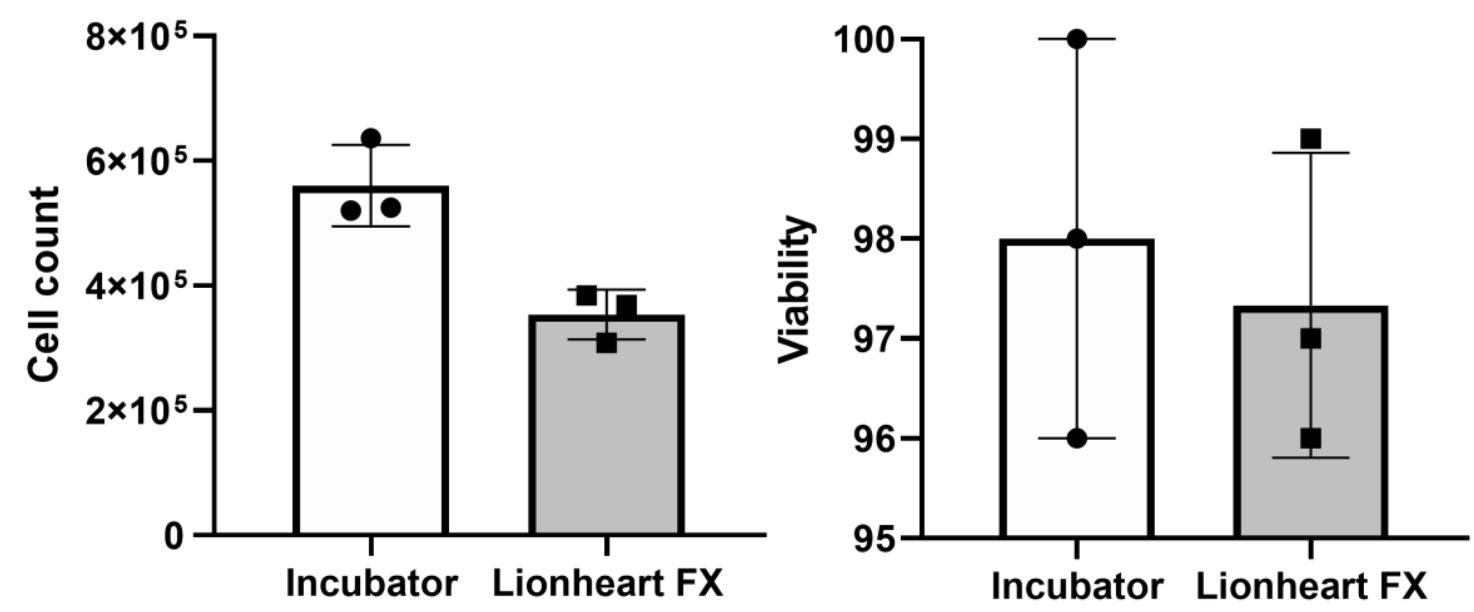

Figure 23. Long-term cell culture of JIMT-1 at static conditions on IBIDI $\mu$-Slide 4 Well Ph+ chip in Incubator vs Lionheart FX. After four days of cell culture with manual renewal of media we can detect that the JIMT-1 cell line grown better on the Hercell 150i incubator, but the viability is not compromised on Lionheart FX.

Like previous experiments, the Adox AcTIVA A22 Syringe Pump was employed to infuse the media, and the auto dosing pump Jecod DP-4 was utilized for draining the old media. This novel device has an intermediate plate with a volume of $700 \mu \mathrm{L}$ below it and allows us to adjust the total volume at that height.

The lid of the $\mu$-Slide 4 Well Ph+ Chip was drilled under laminar flow in two of the wells, twice times. The inlet is located in one of the corners matching with the opening of the intermediate plate. The outlet is on the opposite side but in the middle over the area of the intermediate plate. The purpose is draining only the media above the intermediate plate (Figure 24). Afterward, three of the wells were filled with $700 \mu \mathrm{L}$ of each cell line suspension at a concentration of $1 \times 10^{5}$ cells $/ \mathrm{ml}$ using a standard pipet in sterile conditions through the opening near the corner. The device was transported inside a petri dish and placed inside the Lionheart $\mathrm{FX}$ at $37^{\circ} \mathrm{C}, 5 \% \mathrm{CO}_{2}$.

Immediately, the two drilled wells will be carefully connected with right-angle stainless-steel couplers 22ga x 15mm (Instech Laboratories Inc, USA) through PU tubing, medical-grade, 3Fr, 0.025x.040in (Instech Laboratories Inc, USA). The Adox AcTIVA A22 Syringe Pump was employed to infuse the new media. A syringe Injeckt 


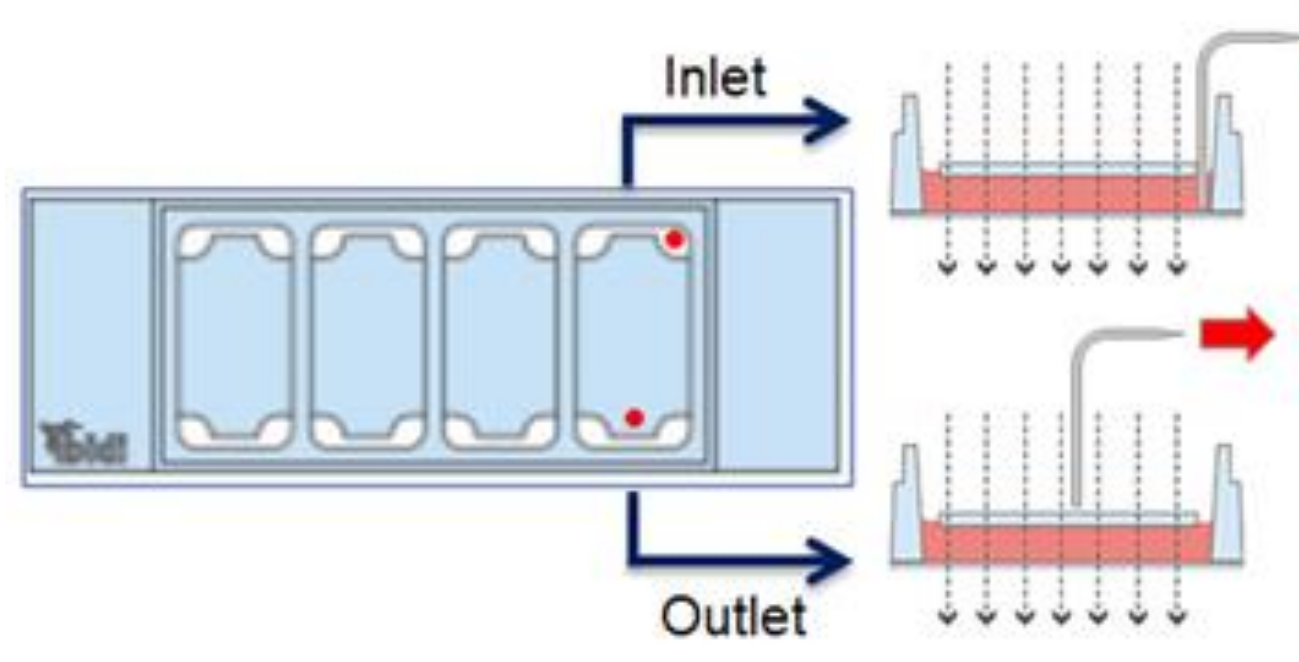

Figure 24. Modified Ibidi $\boldsymbol{\mu - S l i d e ~} 4$ Well $\mathbf{P h}+\mathbf{c h i p}$. Two gaps were made on the lid of commercial Ibidi chips in order to connect steel couplers as inlet and outlet. When it is connected, the inlet is in contact with the culture media, but the outlet only reaches the intermediate plate. The black arrows represent the light path optimized for phase contrast (Modified from Ibidi website)(Ibidi GmbH, n.d.-a).

(B.Braun, Germany) of the necessary volume of media for the whole experiment plus a Luer stub, 22ga x 0.25in (Instech Laboratories Inc, USA) were necessary to connect to the chip appropriately. On the other hand, the peristaltic pump Jecod DP-4 was utilized for draining the old media. The old media was collected in a falcon tube due to a microfluidic lid adapter (Elveflow, France) to assure cells are not being drained (Figure 25)(Adox, n.d.; Cole-Parmer Germany, n.d.; Elveflow, n.d.-a; Ibidi GmbH, n.d.-a). The third well with cells will be used as a static culture control and the last one, with just media, as an evaporation control.

Several aspects should be considered in order to maintain healthy cells. Therefore, our system was developed to avoid bubble formation. It can produce membrane damage and necrosis(Varma \& Voldman, 2018). The levels of humidity and $\mathrm{CO}_{2}$ were monitored with averages of $58 \%$ and $5 \%$, respectively. These values could be reached with the introduction of seven Petri dishes of $60 \mathrm{~mm}$ filled with water.

Another thing to keep in mind is the shear stress produced in the device. It must not exceed physiological values because morphology, distribution, or viability could be altered(Ludwig et al., 1992; Shemesh et al., 2015; Tanzeglock et al., 2009; Varma \& Voldman, 2018). Although we did not perform a simulation of shear stress, considering 
available material from the Ibidi website, it is possible to estimate the impact. Similarly, the $\mu$-Slide I Luer family chips (Figure 26) is characterized by a single channel, offered in different heights(Ibidi $\mathrm{GmbH}, 2016$ ). The shear stress in a rectangular channel is defined by the formula: $T=\eta \times$ Factor (dependent on Slide) $x$ $\Phi$ where, $T=$ shear stress, $\eta=$ dynamical viscosity, $\Phi=$ flow rate. 


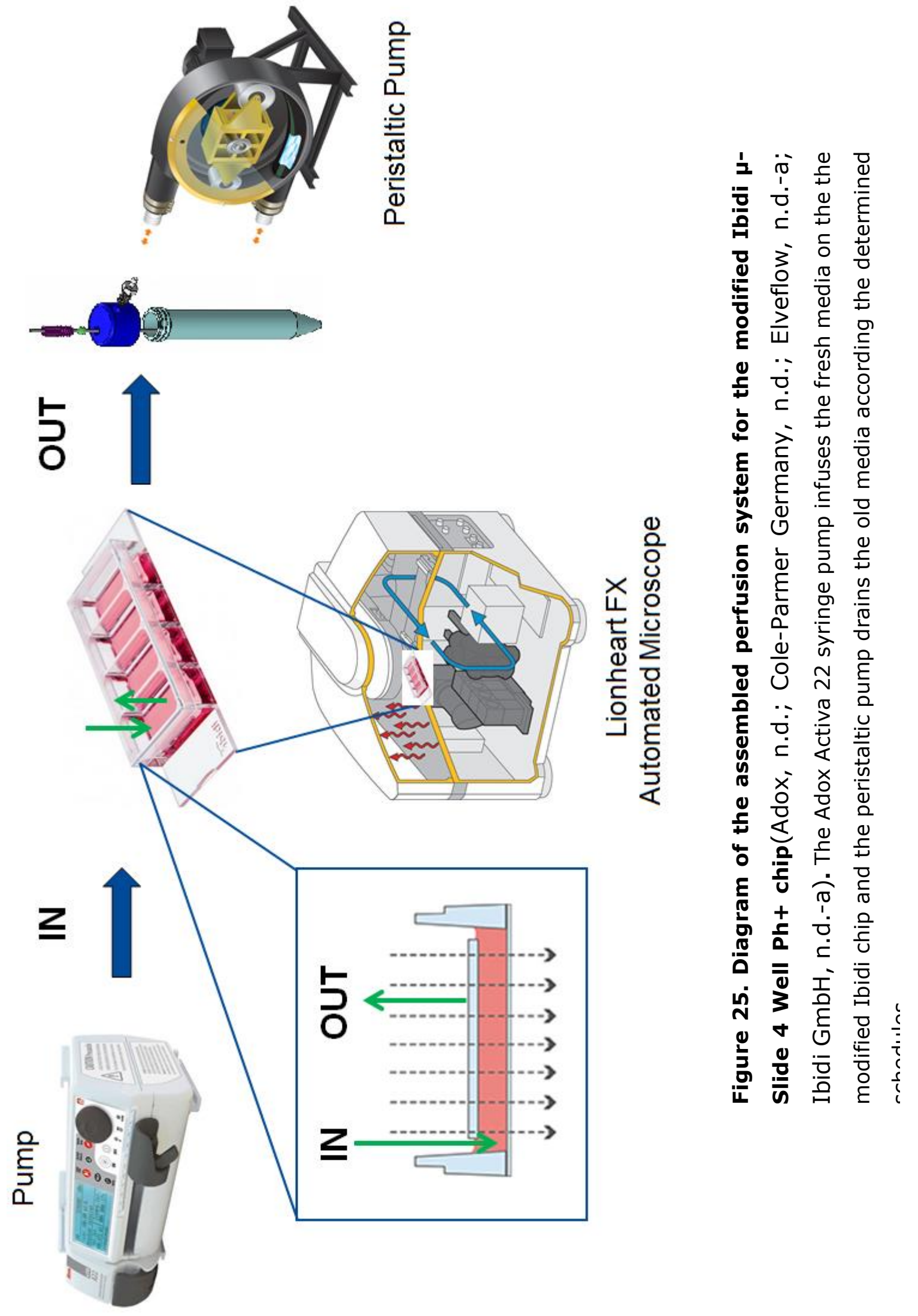



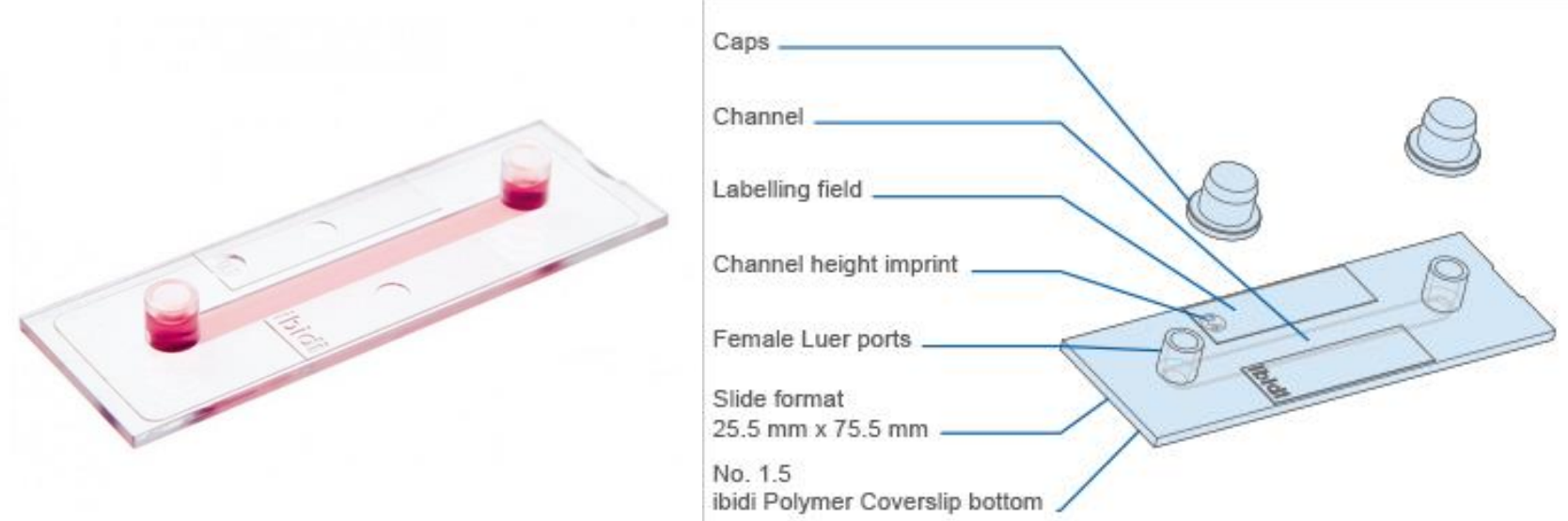

Figure 26. Design of the Ibidi $\mu$-Slide I Luer chip(Ibidi GmbH, n.d.-a).

The dynamical viscosity of DMEM with $10 \%$ serum is approximately $0.0072 \mathrm{dyn} . \mathrm{s} / \mathrm{cm}^{2}$ at $37^{\circ} \mathrm{C}$ and 0.0105 dyn.s $/ \mathrm{cm}^{2}$ at $20^{\circ} \mathrm{C}$. On the other hand, a factor of 34.23 was calculated by exponential regression for the $\mu$-Slide $4 \mathrm{Well} \mathrm{Ph}+$ with a channel height of $3.0 \mathrm{~mm}$ (Figure 27)(Hinderliter et al., 2010; Ibidi $\mathrm{GmbH}, 2016$ ). Considering the highest flow rate on the perfusion strategies $(200 \mu \mathrm{L} / \mathrm{min})$ is estimated between 0.005 $\mathrm{N} / \mathrm{m}^{2}$ and $0.007 \mathrm{~N} / \mathrm{m}^{2}$ of flow shear stress for temperatures among $20^{\circ} \mathrm{C}$ and $37^{\circ} \mathrm{C}$. This value is much lower than the necessary, around $0.25 \mathrm{~N} / \mathrm{m}^{2}$, to generate a significant alteration in morphology and viability in mammalian cells(Ludwig et al., 1992). Besides, there is a tendency of cancer cells to exhibit a biologically enhanced

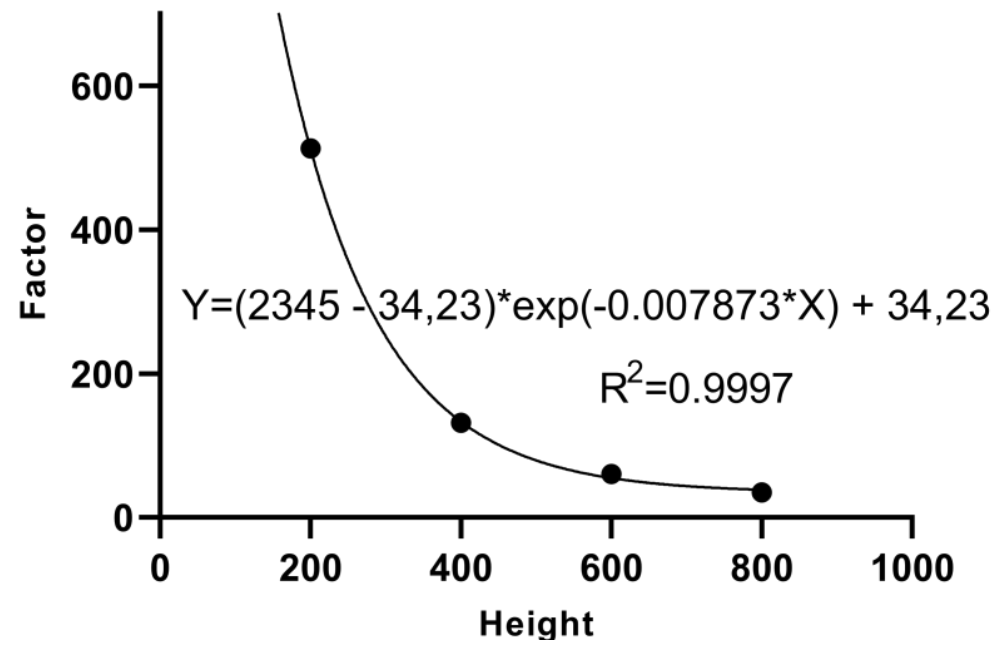

Figure 27. Exponential fit of the factor value employing the available data of the Ibidi $\mu$-Slide I Luer family chips(Ibidi $\mathrm{GmbH}, 2016$ ). The family of $\mu$-Slide I Luer chip is identified with a single channel of diverse height. Making use of the available data, it is possible to approximate the factor on the $\mu$-Slide 4 Well $\mathrm{Ph}+$ Chip to calculate the shear stress. 
capacity to resist fluid shear stress (Barnes et al., 2012). Even though the dimensions of our device are on the edge of microfluidics, we can assume robust perfused cell culture for live-cell imaging.

The imaging process starts immediately after cell seeding. Therefore, cells are in suspension. In consequence, the focus training has been made with samples properly attached to improve the tracking. Nevertheless, eleven focus stacking or Z-stacks, five from above, and five from over the focus height have been set. In this way, we assure the quality of the imaging at each time point.

Regarding the perfusion settings, pumps were configurated to have a starting delay of 8 hours, allowing attachment of cells. The schedule starts on the infusion phase, and the delay prevents cells from getting flushed away.

Several cellular events can be observed with the system, from cell mobility to cell division. As an example, we can observe them in this time-lapse composite of images (Figures 28 and 29). Usually, in these conditions, the changes in the shape of cells to rounded means cell division. The system enables one to follow single cells, and it is possible to detect cytokinesis, where the daughter cell is detached and later starts to interact with other cells to get attached. However, early apoptosis is also characterized by cell rounding due to shrinkage and cytoplasm condensation(Elmore, 2007). Further experiments should be done to image cell death. Some authors suggest adding a low concentration $(0.25 \mu \mathrm{g} / \mathrm{ml})$ of the DNA intercalating fluorescent dye propidium iodide. Nevertheless, we aim to evaluate the cellular growth without fluorochrome interferences and avoiding the possible phototoxicity produced by the lasers.

The cell line JIMT-1 has proved to be a better model than MCF-7 to evaluate the cell behavior in our system. MCF-7 tent to form clusters that not only tricky the focus stabilization since a higher number of signals on different planes are detected but also because the number of clusters can modify the cellular growth. At the same time, the JIMT-1 deploys a monolayer of cells. 


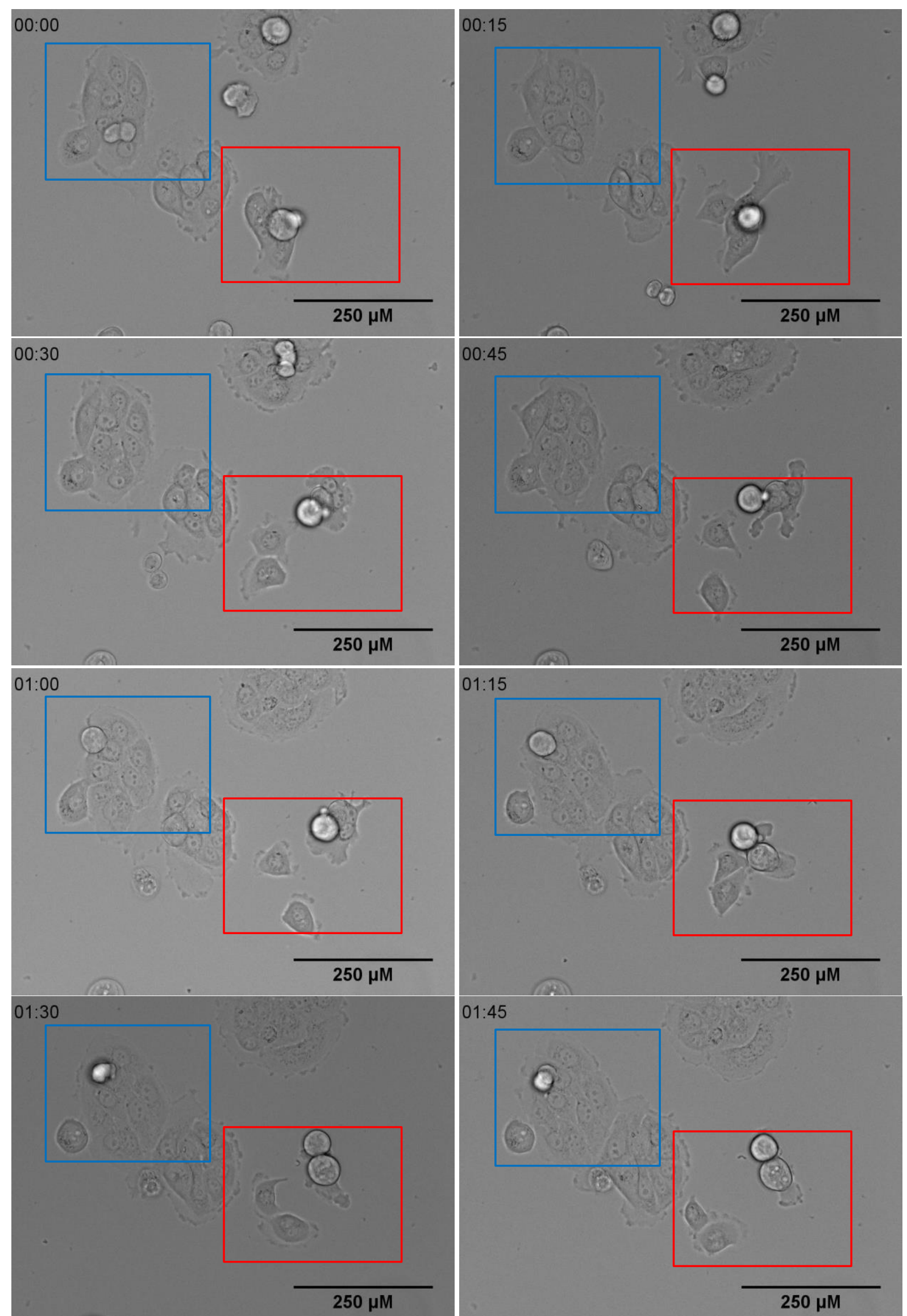

Figure 28. JIMT-1 cellular events on perfused IBIDI $\mu$-Slide $4 \mathrm{Well} \mathbf{P h}+$ chip at 20X. In this brief brightfield time-lapse image sequence it is possible to observe several cellular events as cell division and cell dynamism. 


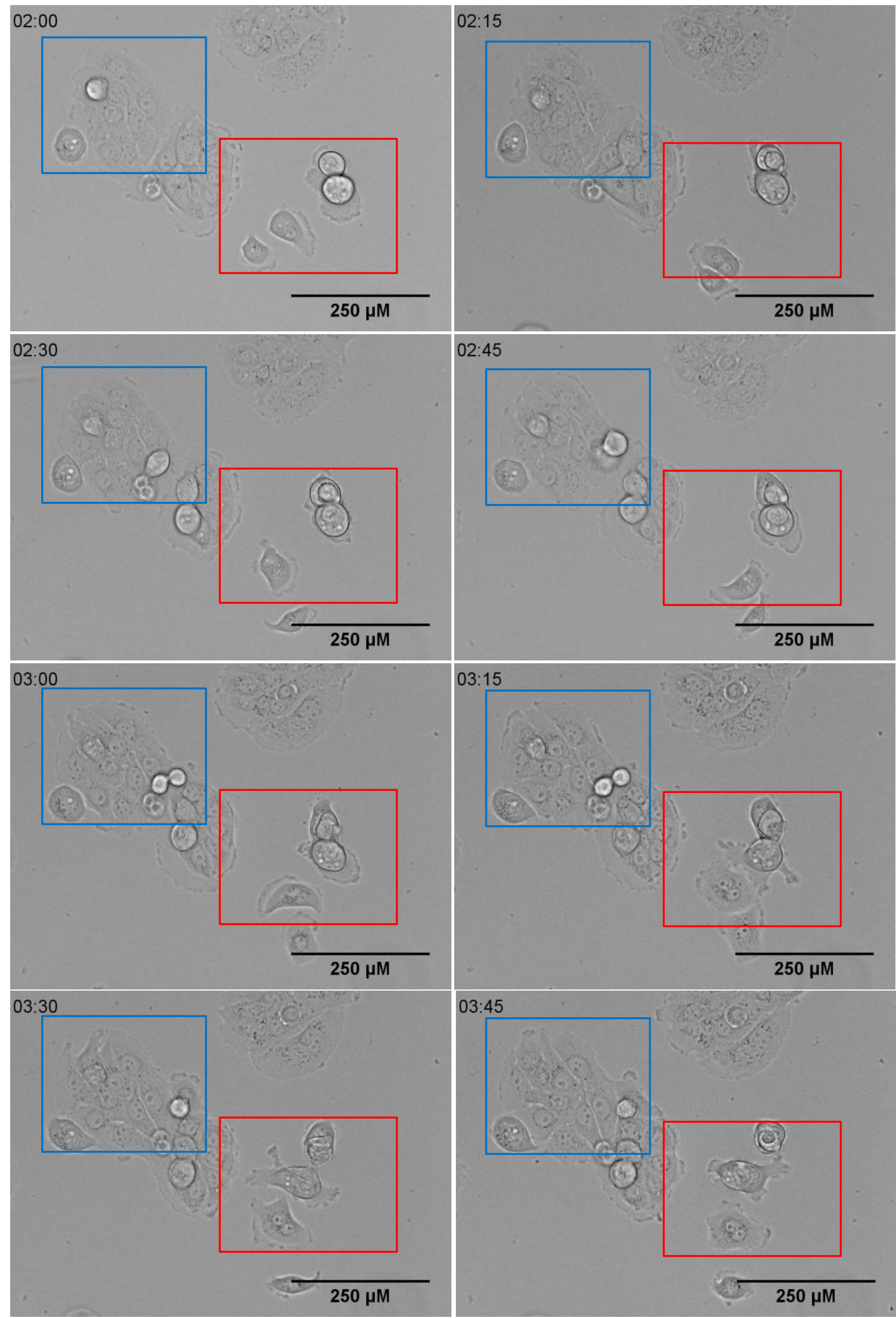

Figure 29. JIMT-1 cellular events on perfused IBIDI $\mu$-Slide $4 \mathrm{Well} \mathbf{P h}+$ chip at 20X. In this brief brightfield time-lapse image sequence it is possible to observe several cellular events as cell division and cell dynamism. 
Finally, to analyze the results of the perfused experiments under different strategies, the traditional protocol of adherent cell counting has been applied at the endpoint. The Bio-Rad TC10 automated cell counter has been considered as the standard method(Hsiung et al., 2013). Besides, the cell counter feature of the Deep Learning algorithm on the image data was performed by Dennis Raith(Raith, 2019). For the image analysis, images at $\mathrm{t}=8 \mathrm{~h}$ where the cells are almost mostly attached have been considered as initial state and images at $t=48 \mathrm{~h}$ as the final state. As we mentioned before, three beacons have been defined per well. The average of the difference between the initial and final state of each beacon describes the respective well. A dissimilar tendency has been observed between both methods. The standard method supports the evidence of a periodic fast media pulse (P1) as the recommended strategy for homogeneous cell culture(Giulitti et al., 2013), manifested in this case as the maximal cell growth (Figure 30). However, no significant differences have been found in the statistical analysis on the TC10 results, between the perfusion strategies in a two-way ANOVA with multiple comparisons tests. On the other hand, the differences between both methods can be attributable to the necessity of training improvement on the Deep Learning algorithm (Figure 31).

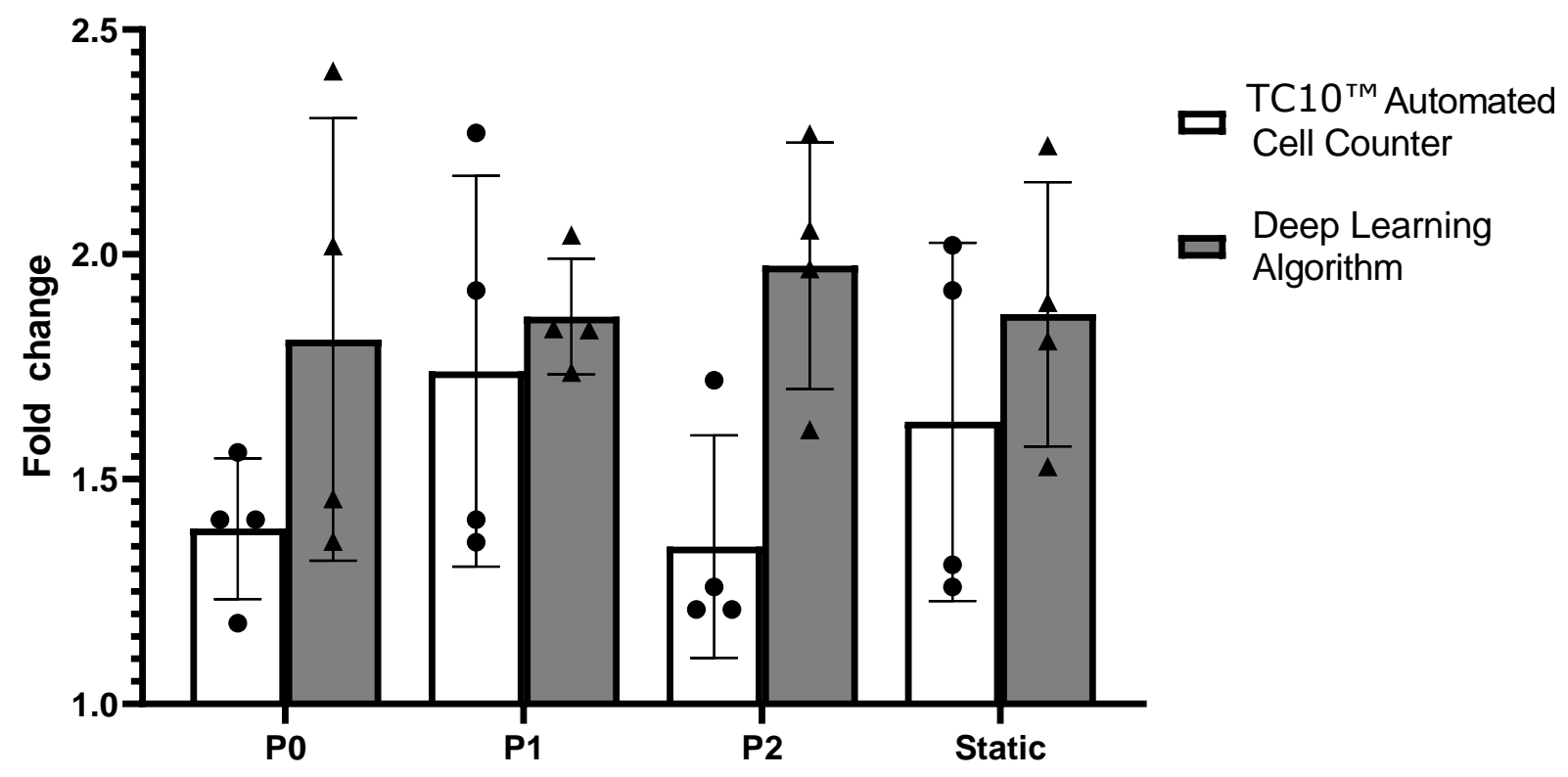

Figure 30. Periodic fast media pulse (P1) achieved the maximal amount of cell number. The JIMT- 1 cell count fold change in perfused conditions at IBIDI $\mu$-Slide 4 Well $\mathrm{Ph}+$ chip has shown the periodic fast media pulse as preferred in terms of cell count after 48 hours on Lionheart FX considering TC10 Automated Cell Counter as standard method. 

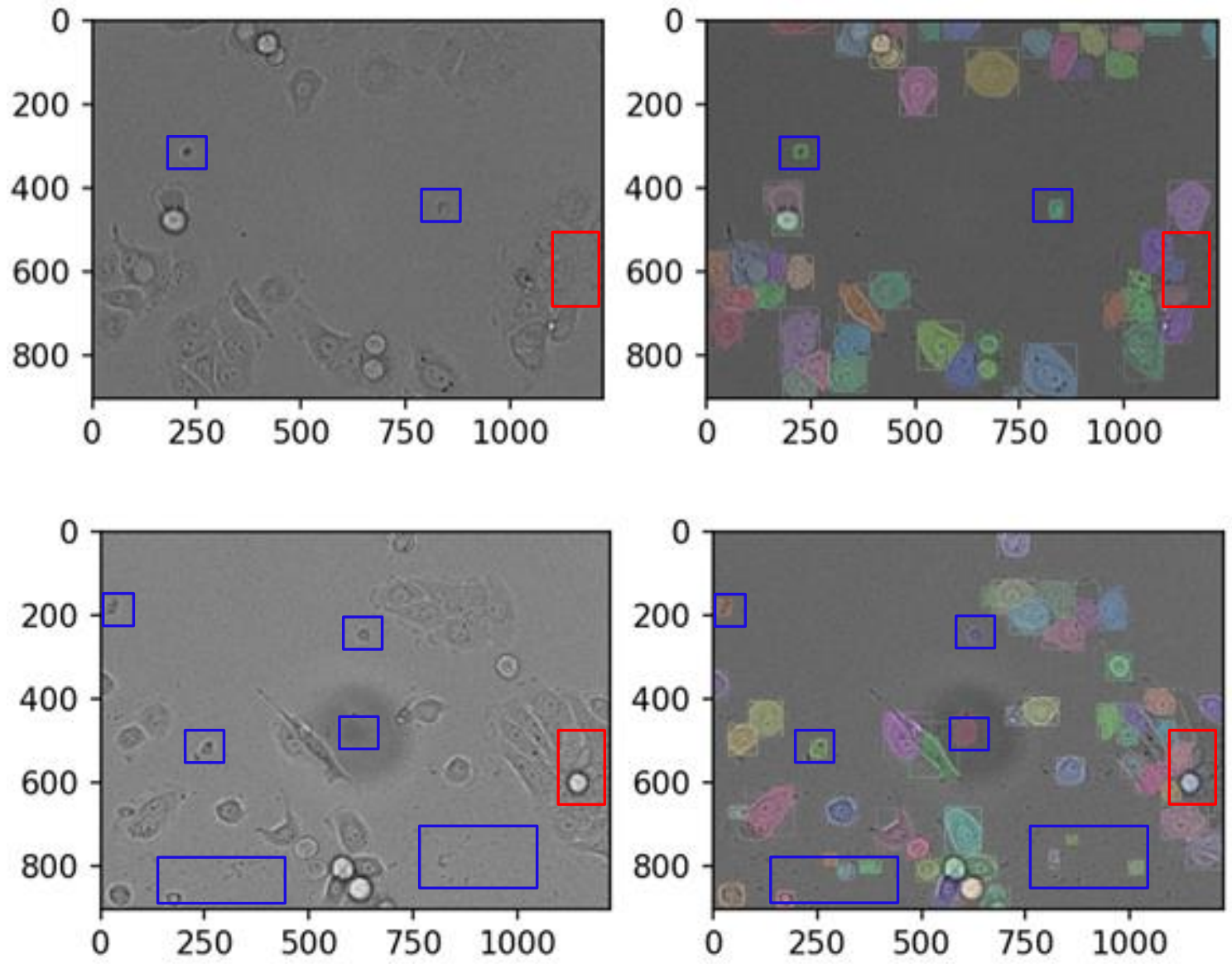

Figure 31. Example of Deep Learning algorithm cell count performance on JIMT-1 image data. Underestimation (Red) and overestimation (Blue). 
Furthermore, we also compared the viability under the different perfusion schedules. Non-significant differences have been detected with Welch's unequal variances t-test (Figure 32), but P1 obtained the lowest percentage of viability. This tendency could be partially explained with the lowest periodicity of the media renewal, where the dead cells are washed out. However, further experiments must be done to claim a relevant difference in cell health. It needs clarifying that the old media was always reviewed in all the conditions without finding a detectable amount of cells (lower than $5 \times 10^{4}$ cells $/ \mathrm{mL})$.

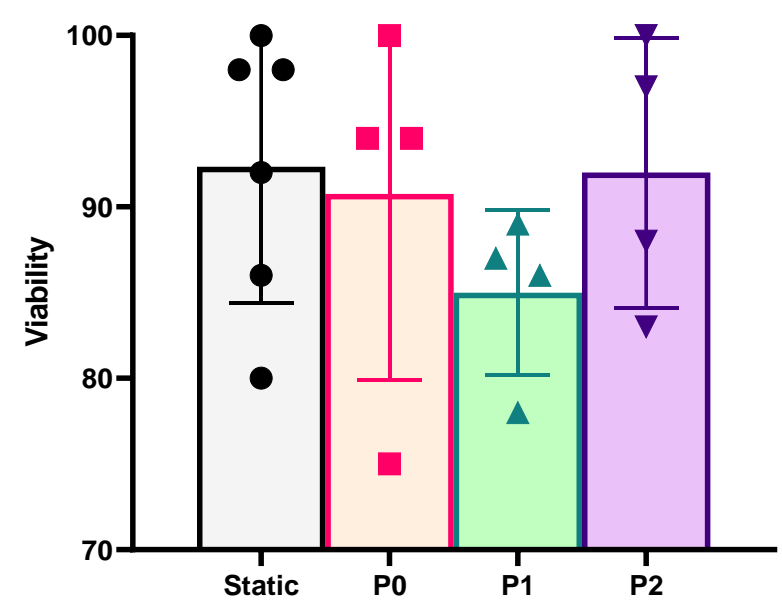

Figure 32. JIMT-1 viability in perfused conditions at IBIDI $\mu$-Slide 4 Well Ph + chip after 2 days on Lionheart FX.

In the end, exploring the relationship between area and cell count, we also performed segmentation-based analysis(X. Chen \& Yu, 2001). Image segmentation is also critical to image processing, tracking, and pattern recognition(Cheng et al., 2001). The image data have been analyzed to measure the area occupied by cells with the Fiji plugin Trainable Weka Segmentation(Arganda-Carreras et al., 2017) and also by Dennis Raith(Raith, 2019) with the Deep Learning algorithm (Figure 33). Similarly, images at $\mathrm{t}=8 \mathrm{~h}$ where cells are predominant attached have been considered as initial state and images at $\mathrm{t}=48 \mathrm{~h}$ as the final state. The average of the difference between the initial and final state of each beacon describes the respective well.

In this case, there is not a standard method identified. Trainable Weka segmentation can be considered as the most widely used for his character of open source. However, 


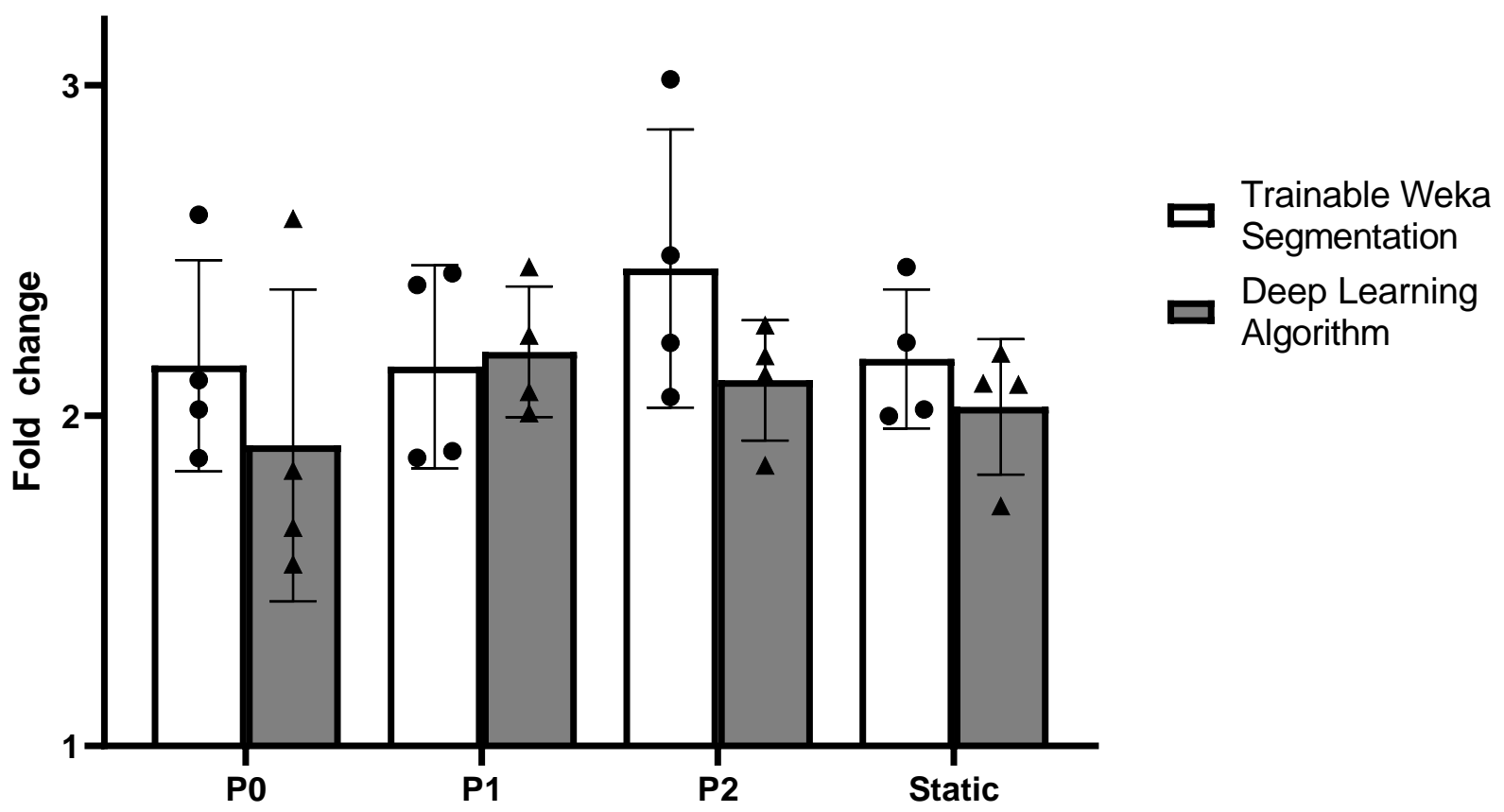

Figure 33. Deep Learning Algorithm segmentation-based analysis fits with the observed results on standard methods of cell counting. In this graph we can observe the same tendency of the deep learning algorithm area measurement as we observed before with the standard method of cell count. In that case, periodic fast media pulse (P1) achieved the maximal amount of cell number with the validated method of cell counting (Fig. 30).

we want to point out that the Deep Learning algorithm measurements showed the same tendency as described before on the cell count analysis and previous works where P1 was the favorite(Giulitti et al., 2013). It is worth noting that the cell count by the TC10 automatic cell counter, unlike the other methods tested at this work, is a validated method.

For those reasons, segmented images of both methods have been reviewed (Figure 34 and 35). The Weka Trainable segmentation performance seems to be the most imprecise in terms of inaccuracy on borders and whole-cell recognition.

However, in order to obtain more reliable results, parameters as the number of beacons that could not be appropriated considering the size of the well should be necessary to be established experimentally. On top of this, improving the amount and quality of data used for training can enhance the performance of the methods. Machine learning algorithms can be trained even to recognize cell death patterns from the brightfield image with the proper training. As an example, changes in the eccentricity of cells can prove apoptotic processes(Kotyk et al., n.d.; Larson \& Banks, 2014). 

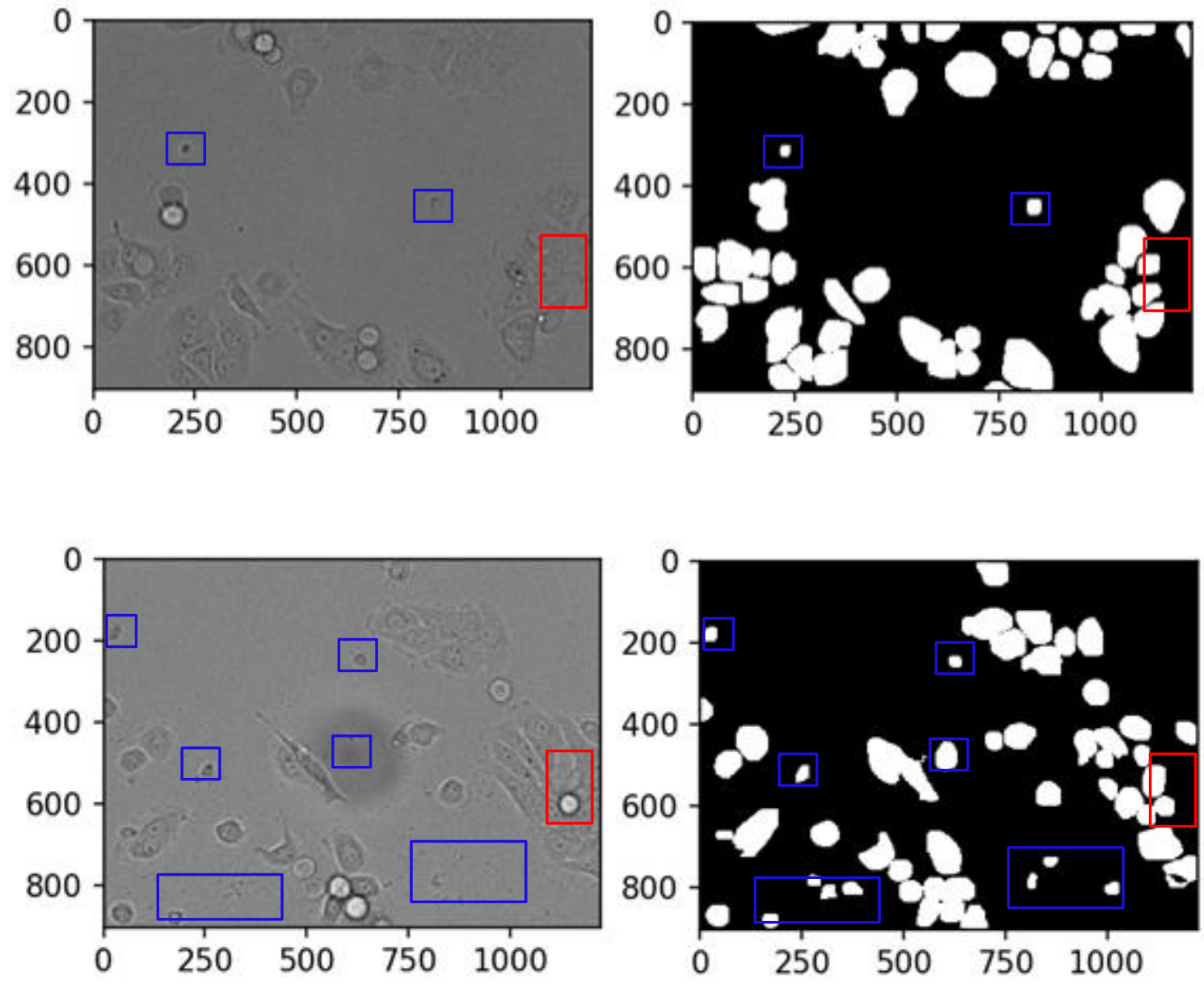

Figure 34. Example of Deep Learning algorithm segmentation performance on JIMT-1 image data. Underestimation (Red) and overestimation (Blue). 


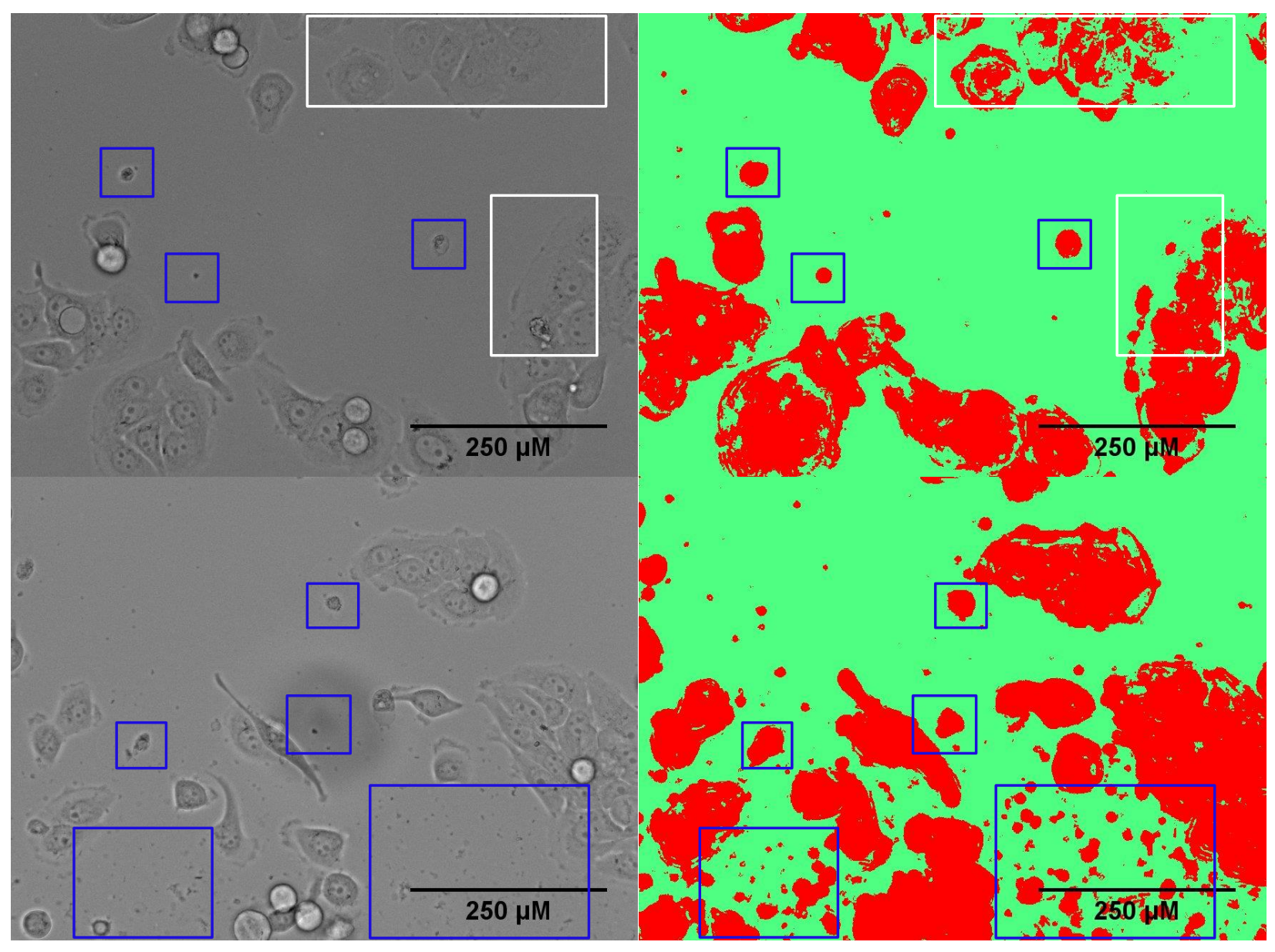

Figure 35. Example of Trainable Weka segmentation performance on JIMT-1 image data. Underestimation (White) and overestimation (Blue). 


\section{Conclusions}

In summary, we developed an accessible and automated perfused system that enables live imaging of cells over more extended periods than found in literature, where usually long-term was considered as experiments no longer than one day(Babic et al., 2018). However, different cell lines could have different behaviors; that is why it is necessary to adjust the setup for each situation. Additionally, the aim of the assay plays a vital role. All the variables must be analyzed and controlled in order to optimize the setup for robust results.

As previous works on the topic of perfused systems(Giulitti et al., 2013), the fastmedia pulse has a clear tendency to be more appropriate for media delivery. Nevertheless, these differences are not statistically significant; that is why it is necessary to repeat more experiments to assure this tendency.

The system has shown to be more robust than conventional available microfluidic systems. While differences were present between the different conditions, they were not meaningful, and the system was not easily affected by minor changes in the perfusion.

The automation on the perfusion reduces human intervention, hence reducing the probabilities of failure by mismanagement, demonstrating the potential of the system to tackle reproducibility issues.

The live-cell imaging feature allows us to analyze cell growth in real-time. We are expanding in innumerable ways the relevance of the system. With the proper amount of data, it will be possible to predict the output of the experiment in earlier times.

Looking further into the future, the system could be applied to simulate the pulse on endothelium cells of blood vessels, renal epithelial cells, or even reproducing metronomic chemotherapy schedules. 


\section{References}

Adox. (n.d.). AcTIVA A22 | Bomba de Infusión a Jeringa. Retrieved March 2, 2020, from http://adox.com.ar/linea/salud/equipamientos/activa-a22/

Ando, Y., Ta, H. P., Yen, D. P., Lee, S. S., Raola, S., \& Shen, K. (2017). A microdevice platform recapitulating hypoxic tumor microenvironments. Scientific Reports, 7(1), 1-12. https://doi.org/10.1038/s41598-017-15583-3

Arganda-Carreras, I., Kaynig, V., Rueden, C., Eliceiri, K. W., Schindelin, J., Cardona, A., \& Seung, H. S. (2017). Trainable Weka Segmentation: A machine learning tool for microscopy pixel classification. Bioinformatics, 33(15), 2424-2426. https://doi.org/10.1093/bioinformatics/btx180

Ayuso, J. M., Virumbrales-Muñoz, M., Lacueva, A., Lanuza, P. M., Checa-Chavarria, E., Botella, P., Fernández, E., Doblare, M., Allison, S. J., Phillips, R. M., Pardo, J., Fernandez, L. J., \& Ochoa, I. (2016). Development and characterization of a microfluidic model of the tumour microenvironment. Scientific Reports, 6(1), 116. https://doi.org/10.1038/srep36086

Azuaje-Hualde, E., García-Hernando, M., Etxebarria-Elezgarai, J., De Pancorbo, M. M., Benito-Lopez, F., \& Basabe-Desmonts, L. (2017). Microtechnologies for cell microenvironment control and monitoring. Micromachines, 8(6). https://doi.org/10.3390/mi8060166

Babic, J., Griscom, L., Cramer, J., \& Coudreuse, D. (2018). An easy-to-build and reusable microfluidic system for live-cell imaging. BMC Cell Biology, 19(1), 8. https://doi.org/10.1186/s12860-018-0158-z

Bae, Y. B., Jang, H. K., Shin, T. H., Phukan, G., Tran, T. T., Lee, G., Hwang, W. R., \& Kim, J. M. (2016). Microfluidic assessment of mechanical cell damage by extensional stress. Lab on a Chip, 16(1), 96-103. https://doi.org/10.1039/c5lc01006c

Baker, M., \& Penny, D. (2016). Is there a reproducibility crisis? Nature, 533(7604), 452-454. https://doi.org/10.1038/533452A 
Barnes, J. M., Nauseef, J. T., \& Henry, M. D. (2012). Resistance to Fluid Shear Stress Is a Conserved Biophysical Property of Malignant Cells. PLOS ONE, 7(12). https://doi.org/10.1371/journal.pone.0050973

Becker, M. W., Simonovich, J. A., \& Phelps, E. A. (2019). Engineered microenvironments and microdevices for modeling the pathophysiology of type 1 diabetes. Biomaterials, 198, 49-62. https://doi.org/10.1016/j.biomaterials.2018.07.002

BioSPX. (n.d.). Lionheart FX. Retrieved March 2, 2020, from https://www.biospx.com/landing/imaging/lfx.html

Bray, F., Ferlay, J., Soerjomataram, I., Siegel, R. L., Torre, L. A., \& Jemal, A. (2018). Global cancer statistics 2018: GLOBOCAN estimates of incidence and mortality worldwide for 36 cancers in 185 countries. CA: A Cancer Journal for Clinicians, 68(6), 394-424. https://doi.org/10.3322/caac.21492

Byun, C. K., Abi-Samra, K., Cho, Y. K., \& Takayama, S. (2014). Pumps for microfluidic cell culture. Electrophoresis, 35(2-3), 245-257. https://doi.org/10.1002/elps.201300205

Chen, L., Yan, C., \& Zheng, Z. (2018). Functional polymer surfaces for controlling cell behaviors. In Materials Today (Vol. 21, Issue 1, pp. 38-59). Elsevier B.V. https://doi.org/10.1016/j.mattod.2017.07.002

Chen, X., \& Yu, C. (2001). Application of some valid methods in cell segmentation. In T. Zhang, B. Bhanu, \& N. Shu (Eds.), Image Extraction, Segmentation, and Recognition (Vol. 4550, pp. 340-344). SPIE. https://doi.org/10.1117/12.441484

Cheng, H. D., Jiang, X. H., Sun, Y., \& Wang, J. (2001). Color image segmentation: Advances and prospects. Pattern Recognition, 34(12), 2259-2281. https://doi.org/10.1016/S0031-3203(00)00149-7

Chirieleison, S. M., Bissell, T. A., Scelfo, C. C., Anderson, J. E., Koebler, D. J., \& Deasy, B. M. (2011). Automated Live Cell Imaging Systems Reveal Dynamic Cell Behavior. https://doi.org/10.1002/btpr.629

Cole-Parmer Germany. (n.d.). Masterflex $®$ Large-Hose Peristaltic Pumps. Retrieved March 9, 2020, from https://www.coleparmer.de/p/masterflex-large-hose- 
peristaltic-pumps/58362

Corsello, S. M., Nagari, R. T., Spangler, R. D., Rossen, J., Kocak, M., Bryan, J. G., Humeidi, R., Peck, D., Wu, X., Tang, A. A., Wang, V. M., Bender, S. A., Lemire, E., Narayan, R., Montgomery, P., Ben-David, U., Garvie, C. W., Chen, Y., Rees, M. G., ... Golub, T. R. (2020). Discovering the anticancer potential of non-oncology drugs by systematic viability profiling. Nature Cancer, 1-14. https://doi.org/10.1038/s43018-019-0018-6

Coutu, D. L., \& Schroeder, T. (2013). Probing cellular processes by long-term live imaging - historic problems and current solutions. Journal of Cell Science, 126(17), 3805-3815. https://doi.org/10.1242/jcs.118349

Danuser, G. (2011). Computer vision in cell biology. Cell, 147(5), 973-978. https://doi.org/10.1016/j.cell.2011.11.001

Demandbase. (n.d.). End-to-End ABM Software | Account-Based Marketing. Retrieved February 19, 2020, from https://www.demandbase.com/

Depaoli, M. R., Bischof, H., Eroglu, E., Burgstaller, S., Ramadani-Muja, J., Rauter, T., Schinagl, M., Waldeck-Weiermair, M., Hay, J. C., Graier, W. F., \& Malli, R. (2019). Live cell imaging of signaling and metabolic activities. In Pharmacology and Therapeutics (Vol. 202, pp. 98-119). Elsevier Inc. https://doi.org/10.1016/j.pharmthera.2019.06.003

Desmet, A. S., Cirillo, C., Tack, J., Vandenberghe, W., \& Berghe, P. Vanden. (2017). Live calcium and mitochondrial imaging in the enteric nervous system of parkinson patients and controls. ELife, 6. https://doi.org/10.7554/eLife.26850

Ecker, D. M., Jones, S. D., \& Levine, H. L. (2015). The therapeutic monoclonal antibody market. MAbs, 7(1), 9-14. https://doi.org/10.4161/19420862.2015.989042

Elmore, S. (2007). Apoptosis: A Review of Programmed Cell Death. Toxicologic Pathology, 35(4), 495-516. https://doi.org/10.1080/01926230701320337

Elveflow. (n.d.-a). Microfluidic instruments specialist - Microfluidics innovation center. Retrieved February 17, 2020, from https://www.elveflow.com/

Elveflow. (n.d.-b). Syringe pumps and microfluidics . Retrieved February 19, 2020, 
from https://www.elveflow.com/microfluidic-reviews/microfluidic-flowcontrol/syringe-pumps-and-microfluidics/

Farina, M., Ballerini, A., Fraga, D. W., Nicolov, E., Hogan, M., Demarchi, D., Scaglione, F., Sabek, O. M., Horner, P., Thekkedath, U., Gaber, O. A., \& Grattoni, A. (2017). 3D Printed Vascularized Device for Subcutaneous Transplantation of Human $\begin{array}{llll}\text { Islets. Biotechnology } 12(9), & 1700169 .\end{array}$ https://doi.org/10.1002/biot.201700169

FDA. (n.d.). What Is an Infusion Pump? Retrieved February 19, 2020, from https://www.fda.gov/medical-devices/infusion-pumps/what-infusion-pump

Ferrari, M., Cirisano, F., \& Morán, M. C. (2019). Mammalian Cell Behavior on Hydrophobic Substrates: Influence of Surface Properties. Colloids and Interfaces, 3(2), 48. https://doi.org/10.3390/colloids3020048

Frigault, M. M., Lacoste, J., Swift, J. L., \& Brown, C. M. (2009). Live-cell microscopy Tips and tools. Journal of Cell Science, 122(6), 753-767. https://doi.org/10.1242/jcs.033837

Geraghty, R. J., Capes-Davis, A., Davis, J. M., Downward, J., Freshney, R. I., Knezevic, I., Lovell-Badge, R., Masters, J. R., Meredith, J., Stacey, G. N., Thraves, P., Vias, M. , \& Cancer Research UK. (2014). Guidelines for the use of cell lines in biomedical research. British Journal of Cancer, 111(6), 1021-1046. https://doi.org/10.1038/bjc.2014.166

Gerstung, M., Jolly, C., Leshchiner, I., Dentro, S. C., Yu, K., Tarabichi, M., Deshwar, A., \& Wintersinger, J. (2017). The evolutionary history of 2 ,658 cancers. BioRxiv, 578(November 2019). https://doi.org/10.1101/161562

Giulitti, S., Magrofuoco, E., Prevedello, L., \& Elvassore, N. (2013). Optimal periodic perfusion strategy for robust long-term microfluidic cell culture. Lab on a Chip, 13(22), 4430-4441. https://doi.org/10.1039/c3lc50643f

Green, J. A., \& Yamada, K. M. (2007). Three-dimensional microenvironments modulate fibroblast signaling responses. In Advanced Drug Delivery Reviews (Vol. 59, Issue 13, pp. 1293-1298). NIH Public Access. https://doi.org/10.1016/j.addr.2007.08.005 
Griffiths, B. (1990). Perfusion Systems for Cell Cultivation. In Large-Scale Mammalian Cell Culture Technology (Vol. 10, pp. 217-250). Routledge. https://doi.org/10.1201/9780203749166-9

Held, P., \& Mongeon, R. (2019). Advances in Live Cell Imaging Applications: Quantifying real time cellular responses from seconds to weeks. BioTek. https://www.biotek.com/resources/webinars/advances-in-live-cell-imagingapplications-quantifying-real-time-cellular-responses-from-seconds-to-weeks/

Hidalgo San Jose, L., Stephens, P., Song, B., \& Barrow, D. (2018). Microfluidic Encapsulation Supports Stem Cell Viability, Proliferation, and Neuronal Differentiation. Tissue Engineering Part C: Methods, 24(3), 158-170. https://doi.org/10.1089/ten.tec.2017.0368

Hinderliter, P. M., Minard, K. R., Orr, G., Chrisler, W. B., Thrall, B. D., Pounds, J. G., \& Teeguarden, J. G. (2010). ISDD: A computational model of particle sedimentation, diffusion and target cell dosimetry for in vitro toxicity studies. In Particle and Fibre Toxicology (Vol. 7). https://doi.org/10.1186/1743-8977-7-36

Hines, W. C., Su, Y., Kuhn, I., Polyak, K., \& Bissell, M. J. (2014). Sorting out the FACS: A devil in the details. Cell Reports, 6(5), 779-781. https://doi.org/10.1016/j.celrep.2014.02.021

Hsiung, F., Mccollum, T., Hefner, E., \& Rubio, T. (2013). Comparison of Count Reproducibility, Accuracy, and Time to Results between a Hemocytometer and the TC20 TM Automated Cell Counter. http://www.biorad.com/webroot/web/pdf/lsr/literature/Bulletin_6003.pdf

Huether-Franken, C. (2017, March 29). The First Mother of Cell Culture. Eppendorf Handling Solutions. https://handling-solutions.eppendorf.com/cellhandling/about-cells-and-culture/detailview/news/the-first-mother-of-cellculture/

Ibidi GmbH. (n.d.-a). Labware | Advanced Slides, Dishes \& Plates for Cell Culture. Retrieved March 2, 2020, from https://ibidi.com/12-labware

Ibidi GmbH. (n.d.-b). Live Cell Imaging | Experiment Requirements. Retrieved March 5, 2020, from https://ibidi.com/content/338-the-live-cell-imaging-experiment 
Ibidi GmbH. (2016). Application Note 11 Shear stress and shear rates for ibidi microslides- Based on numerical calculations. In Version 4,1 (Issue March 2016). http://ibidi.com/fileadmin/support/application_notes/AN11_Shear_stress.pdf

IEC

$$
\text { 60601-2-24:2012, }
$$

https://www.iecee.org/dyn/www/f?p=106:49:0::::FSP_STD_ID:2635

ImageJ. (n.d.). Scripting the Trainable Weka Segmentation. Retrieved March 2, 2020, from https://imagej.net/Scripting_the_Trainable_Weka_Segmentation

Jecod. (n.d.). Jecod Dosing Pumps | D-D The Aquarium Solution. Retrieved March 2, 2020, from https://www.theaquariumsolution.com/product/3079/276

Jedrzejczak-Silicka, M. (2017). History of Cell Culture. In New Insights into Cell Culture Technology. https://doi.org/10.5772/66905

Jensen, E. C. (2013). Overview of Live-Cell Imaging: Requirements and Methods Used. Anatomical Record, 296(1), 1-8. https://doi.org/10.1002/ar.22554

Jørgensen, F., \& Lambert, P. (2008). Accurate biopharmaceutical dispensing: Peristaltic or piston pumps? Innovations in Pharmaceutical Technology, 26, 7880.

Kolnik, M., Tsimring, L. S., \& Hasty, J. (2012). Vacuum-assisted cell loading enables shear-free mammalian microfluidic culture. Lab on a Chip, 12(22), 4732-4737. https://doi.org/10.1039/c2lc40569e

Kotyk, T., Chakraborty, S., Ashour, A. S., Dey, N., \& Balas, V. E. (n.d.). Apoptosis Analysis in Classification Paradigm: A Neural Network based Approach.

Lage, O. M., Ramos, M. C., Calisto, R., Almeida, E., Vasconcelos, V., \& Vicente, F. (2018). Current screening methodologies in drug discovery for selected human diseases. Marine Drugs, 16(8), 1-31. https://doi.org/10.3390/md16080279

Larson, B., \& Banks, P. (2014). Use of Phase Contrast Imaging to Track Morphological Cellular Changes due to Apoptotic Activity. www.biotek.com

Liu, Y., Chen, X., Han, W., \& Zhang, Y. (2017). Tisagenlecleucel, an approved antiCD19 chimeric antigen receptor T-cell therapy for the treatment of leukemia. Drugs of Today, 53(11), 597. https://doi.org/10.1358/dot.2017.53.11.2725754 
Liu, Z., Lavis, L. D., \& Betzig, E. (2015). Imaging Live-Cell Dynamics and Structure at the Single-Molecule Level. In Molecular Cell (Vol. 58, Issue 4, pp. 644-659). Cell Press. https://doi.org/10.1016/j.molcel.2015.02.033

Ludwig, A., Tomeczkowski, J., \& Kretzmer, G. (1992). Influence of the temperature on the shear stress sensitivity of adherent BHK 21 cells. Applied Microbiology and Biotechnology, 38(3), 323-327. https://doi.org/10.1007/BF00170080

Magidson, V. and, \& Khodjakov, A. (2013). Circumventing photodamage in live-cell microscopy. Methods Cell Biol., 1-15. https://doi.org/10.1016/B978-0-12407761-4.00023-3.

Maiti, R. (2014). Metronomic chemotherapy. Journal of Pharmacology and Pharmacotherapeutics, 5(3), 186-192. https://doi.org/10.4103/0976500X.136098

Mertelsmann, R., \& Georg, M. (2016). Cancer: Modeling evolution and natural selection, the "Mitosis Game." Journal of Science, Humanities and Arts, 3(1). https://doi.org/10.17160/josha.3.1.100

MIAP. (n.d.). ZEISS AxioObserver. Retrieved March 2, 2020, from https://miap.eu/microscopy/wide-field-microscopy/lighthouse/zeissaxioobserver

Nie, J., Gao, Q., Wang, Y., Zeng, J., Zhao, H., Sun, Y., Shen, J., Ramezani, H., Fu, Z., Liu, Z., Xiang, M., Fu, J., Zhao, P., Chen, W., \& He, Y. (2018). Vessel-on-a-chip with Hydrogel-based Microfluidics. Small, 14(45), 1-14. https://doi.org/10.1002/smll.201802368

NIH Office of Science Policy. (n.d.). Significant Research Advances Enabled by HeLa Cells. Retrieved February 11, 2020, from https://osp.od.nih.gov/scientificsharing/hela-cells-timeline/

Olmos, C. M., Penãherrera, A., Rosero, G., Vizuete, K., Ruarte, D., Follo, M., Vaca, A., Arroyo, C. R., Debut, A., Cumbal, L., Pérez, M. S., Lerner, B., \& Mertelsmann, R. (2020). Cost-effective fabrication of photopolymer molds with multi-level microstructures for pdms microfluidic device manufacture. RSC Advances, 10(7), 4071-4079. https://doi.org/10.1039/c9ra07955f 
Oña, L., \& Lachmann, M. (2020). Signalling architectures can prevent cancer evolution. Scientific Reports. https://doi.org/10.1038/s41598-020-57494-w

Pamies, D., Bal-Price, A., Chesné, C., Coecke, S., Dinnyes, A., Eskes, C., Grillari, R., Gstraunthaler, G., Hartung, T., Jennings, P., Leist, M., Martin, U., Passier, R., Schwamborn, J. C., Stacey, G. N., Ellinger-Ziegelbauer, H., \& Daneshian, M. (2018). Advanced Good Cell Culture Practice for human primary, stem cellderived and organoid models as well as microphysiological systems. Altex, 35(3), 353-378. https://doi.org/10.14573/altex.1710081

Pampaloni, F., Reynaud, E. G., \& Stelzer, E. H. K. (2007). The third dimension bridges the gap between cell culture and live tissue. Nature Reviews Molecular Cell Biology, 8(10), 839-845. https://doi.org/10.1038/nrm2236

Pantziarka, P., Verbaanderd, C., Sukhatme, V., Rica Capistrano, I., Crispino, S., Gyawali, B., Rooman, I., Van Nuffel, A. M. T., Meheus, L., Sukhatme, V. P., \& Bouche, G. (2018). Redo_DB: The repurposing drugs in oncology database. Ecancermedicalscience, 12. https://doi.org/10.3332/ecancer.2018.886

Pereiro, I., Fomitcheva Khartchenko, A., Petrini, L., \& Kaigala, G. V. (2019). Nip the bubble in the bud: A guide to avoid gas nucleation in microfluidics. In Lab on a Chip (Vol. 19, Issue 14, pp. 2296-2314). Royal Society of Chemistry. https://doi.org/10.1039/c9lc00211a

Raith, D. (2019). Exploration of Reinforcement Learning for Vision-based Automated Perfusion Systems. Albert-Ludwigs-University Freiburg.

Schindelin, J., Arganda-Carreras, I., Frise, E., Kaynig, V., Longair, M., Pietzsch, T., Preibisch, S., Rueden, C., Saalfeld, S., Schmid, B., Tinevez, J. Y., White, D. J., Hartenstein, V., Eliceiri, K., Tomancak, P., \& Cardona, A. (2012). Fiji: An opensource platform for biological-image analysis. In Nature Methods (Vol. 9, Issue 7, pp. 676-682). https://doi.org/10.1038/nmeth.2019

Shemesh, J., Jalilian, I., Shi, A., Heng Yeoh, G., Knothe Tate, M. L., \& Ebrahimi Warkiani, M. (2015). Flow-induced stress on adherent cells in microfluidic devices. In Lab on a Chip (Vol. 15, Issue 21, pp. 4114-4127). Royal Society of Chemistry. https://doi.org/10.1039/c5lc00633c

Sommer, C., \& Gerlich, D. W. (2013). Machine learning in cell biology-teaching 
computers to recognize phenotypes. Journal of Cell Science, 126(24), 5529-5539. https://doi.org/10.1242/jcs.123604

Strober, W. (2015). Trypan Blue Exclusion Test of Cell Viability. Current Protocols in Immunology, 111(1), A3.B.1-A3.B.3. https://doi.org/10.1002/0471142735.ima03bs111

Tanzeglock, T., Soos, M., Stephanopoulos, G., \& Morbidelli, M. (2009). Induction of mammalian cell death by simple shear and extensional flows. Biotechnology and Bioengineering, 104(2), 360-370. https://doi.org/10.1002/bit.22405

Topper, J. N., \& Gimbrone, M. A. (1999). Blood flow and vascular gene expression: fluid shear stress as a modulator of endothelial phenotype. Molecular Medicine Today, 5(1), 40-46. https://doi.org/10.1016/s1357-4310(98)01372-0

Treloar, N. J., Fedorec, A. J. H., \& Barnes, C. P. (2018). Deep reinforcement learning for the control of bacterial populations in bioreactors. 1-16. https://doi.org/10.1101/457366

Trounson, A., Thakar, R. G., Lomax, G., \& Gibbons, D. (2011). Clinical trials for stem cell therapies. BMC Medicine, 9(1), 52. https://doi.org/10.1186/1741-7015-9-52

Varma, S., \& Voldman, J. (2018). Caring for cells in microsystems: principles and practices of cell-safe device design and operation. Lab on a Chip, 18(22), 33333352. https://doi.org/10.1039/C8LC00746B

Vijayavenkataraman, S., Yan, W. C., Lu, W. F., Wang, C. H., \& Fuh, J. Y. H. (2018). 3D bioprinting of tissues and organs for regenerative medicine. In Advanced Drug Delivery Reviews (Vol. 132, pp. 296-332). Elsevier B.V. https://doi.org/10.1016/j.addr.2018.07.004

Waks, A. G., \& Winer, E. P. (2019). Breast Cancer Treatment: A Review. In JAMA Journal of the American Medical Association (Vol. 321, Issue 3, pp. 288-300). American Medical Association. https://doi.org/10.1001/jama.2018.19323

Weinger, M. B., \& Kline, A. (2016). Reflections on the current state of infusion therapy. Biomedical Instrumentation and Technology, 50(4), 253-262. https://doi.org/10.2345/0899-8205-50.4.253

Whitesides, G. M. (2006). The origins and the future of microfluidics. In Nature (Vol. 
442, Issue 7101, pp. 368-373). Nature Publishing Group. https://doi.org/10.1038/nature05058

WHO. (n.d.). Cancer. Retrieved February 6, 2020, from https://www.who.int/en/news-room/fact-sheets/detail/cancer

Willyard, C. (2016). Cancer: An evolving threat. Nature Medicine, 532, 166-168. https://doi.org/10.1038/nm0908-904

Yeo, L. Y., Chang, H. C., Chan, P. P. Y., \& Friend, J. R. (2011). Microfluidic devices for bioapplications. Small, 7(1), 12-48. https://doi.org/10.1002/smll.201000946

Zhu, Z., Geng, Y., Yuan, Z., Ren, S., Liu, M., Meng, Z., \& Pan, D. (2019). A BubbleFree Microfluidic Device for Easy-to-Operate Immobilization, Culturing and Monitoring of Zebrafish Embryos. Micromachines, 10(3), 168. https://doi.org/10.3390/mi10030168 


\begin{tabular}{|c|c|}
\hline $\begin{array}{l}\text { Name: } \\
\text { Telephone: } \\
\text { Email: } \\
\text { Date of birth: } \\
\text { Nationality: }\end{array}$ & $\begin{array}{l}\text { Dario Gabriel Ruarte } \\
+4901774771303 \\
\text { dario.ruarte@students.uni-freiburg.de } \\
\text { March 18, } 1989 \\
\text { Argentinian }\end{array}$ \\
\hline
\end{tabular}

2018 - Present MSc Biomedical Sciences at University of Freiburg (IMBS)

Freiburg, GE

Thesis Lab: Mertelsmann, R / Follo, M (Internal Medicine I)

Thesis topic: Optimization of long-term breast cancer cell culture using live imaging in an automated perfusion system.

Director: Prof. Dr. Joschka Bödecker (Neurobotics Lab)

2018 - Present MSc Biomedical Sciences at University of Buenos Aires (IMBS)

Buenos Aires, AR

2019

Diploma of Advanced Studies in Biomedical Sciences at University of Freiburg

2007-2016 Pharmacist at University of Córdoba

Córdoba, AR

Practical semester: Dept. of Pharmacovigilance and Scientific Information at the Laboratorio de Hemoderivados U.N.C.

Work experience and Leadership

2019 - $2020 \quad$ Research Intern/Students Coordinator AG Mertelsmann/Follo

Cell culture. Live-imaging. Image Analysis. Microfluidics. Breast cancer cell lines. T-cells isolation and expansion. Erythroid differentiation of K562 cell line. Flow cytometry. Students supervision.

$2018 \quad$ Pharmacist - Team Leader at Farmacity

2014 - 2017 Hospital Pharmacist at Sanatorio Allende Nueva Córdoba

2012 - $2014 \quad$ Hospital Pharmacy Administrative at Sanatorio del Salvador

2013

Ad-Honorem assistant on Pharmacognosy Dept. at Universidad Nacional de Córdoba (U.N.C.)

Freiburg, GE

\section{Courses/Seminars/Symposiums}

2019

ICN-ZKS Freiburg Symposium

Clinical Trials in the Global and Digital World

$2019 \quad$ Cell and gene therapy module at the Institute for Transfusion Medicine and Gene Therapy \& Center for Chronic Immunodeficiency

2018 Molecular tumor board workshop at Boerries Lab for Systems Biology and Systems Medicine.

2016

$$
\text { Training and updating course in Good Practices of Clinical Research at }
$$

Fundación de Estudios Farmacológicos y de Medicamentos (FEFYM)

Freiburg, GE

Freiburg, GE

Freiburg, GE

Córdoba, AR

\section{Publications/Congress/Scholarships}

2020 Olmos, C.; Peñaherrera, A. et al. Cost-effective fabrication of photopolymer molds with multi-level microstructures for PDMS microfluidic device manufacture. RSC Adv., 2020, 10, 4071-4079. DOI: 10.1039/C9RA07955F.

2019 - Present Biothera-Roland Mertelsmann Foundation Scholarship

2018

German Academic Exchange Service (DAAD) Scholarship

2016

Profile use of Human Serum Albumin 20\% U.N.C.: Interdisciplinary work of pharmacovigilance. Oral presentation at the 27th congress of Sociedad Argentina de Terapia Intensiva (SATI) 